Florida International University

FIU Digital Commons

FIU Electronic Theses and Dissertations

University Graduate School

7-27-2018

\title{
Religion and Ethnicity among Afro-Colombian Muslims in Buenaventura (Colombia)
}

Diego Giovanni Castellanos

Florida International University, dcast057@fiu.edu

Follow this and additional works at: https://digitalcommons.fiu.edu/etd

Part of the Islamic Studies Commons, Latin American Studies Commons, Race and Ethnicity

Commons, and the Social and Cultural Anthropology Commons

\section{Recommended Citation}

Castellanos, Diego Giovanni, "Religion and Ethnicity among Afro-Colombian Muslims in Buenaventura (Colombia)" (2018). FIU Electronic Theses and Dissertations. 3861.

https://digitalcommons.fiu.edu/etd/3861

This work is brought to you for free and open access by the University Graduate School at FIU Digital Commons. It has been accepted for inclusion in FIU Electronic Theses and Dissertations by an authorized administrator of FIU Digital Commons. For more information, please contact dcc@fiu.edu. 


\section{FLORIDA INTERNATIONAL UNIVERSITY}

Miami, Florida

\section{RELIGION AND ETHNICITY AMONG AFRO-COLOMBIAN MUSLIMS IN BUENAVENTURA (COLOMBIA)}

A thesis submitted in partial fulfillment of the

requirements for the degree of

MASTER OF ARTS

in

RELIGIOUS STUDIES

by

Diego Giovanni Castellanos 
To: Dean John F. Stack

Steven J. Green School of International and Public Affairs

This thesis, written by Diego Giovanni Castellanos, and entitled Religion and Ethnicity among Afro-Colombian Muslims in Buenaventura (Colombia), having been approved in respect to style and intellectual content, is referred to you for judgment.

We have read this thesis and recommend that it be approved.

$\begin{array}{r}\text { Albert Wuaku } \\ \hline \text { Erik Larson } \\ \hline \text { Ana Maria Bidegain, Major Professor }\end{array}$

Date of Defense: July 27, 2018

The thesis of Diego Giovanni Castellanos is approved.

Dean John F. Stack

Steven J. Green School of International and Public Affairs

Andrés G. Gil

Vice President for Research and Economic Development and Dean of the University Graduate School

Florida International University, 2018 
(C) Copyright 2018 Diego Giovanni Castellanos

All rights reserved. 


\section{DEDICATION}

This thesis is dedicated to my wife, Joen Delgado, and my beautiful daughter, Sara Sofia, for their love and patience. 


\section{ACKNOWLEDGMENTS}

I want to thank the professors of the Religious Studies Department at FIU, who offered me their support in several difficult situations during the development of my studies and the preparation of this thesis. To all of you, thank you.

In particular, I would like to thank Professor Ana María Bidegain for her unconditional support throughout the different stages of this work, for her thoughtful suggestions and comments, and most importantly, for continuing to believe in me and in my work.

I want to thank Professor Albert Wuaku, for his many recommendations and valuable contributions in the courses I took with him. Also, I am grateful to Professor Erik Larson, who was an indispensable guide, both in his courses and outside them. Thanks to both professors I was able to develop a broader framework for this research.

I especially want to thank Professor Iqbal Akhtar, who without knowing me read my work and supported my re-entry to the program to complete this process.

I would also like to thank the Latin American and Caribbean Center, which supported me through the Tinker Field Research Grant to carry out my fieldwork in 2011. Without that support, this research would have experienced greater difficulties.

I also want to thank Professor Mercedes Vigon, who was interested in a documentary about the daily life of the Muslim community of Buenaventura. The final product, launched in 2014, was well received by the community and helped me to reflect on the facts described here. 
I would like to thank the members of the Muslim community of Buenaventura, who welcomed me and offered their cooperation. A special thanks to Sheikh Munir Valencia, and his family, for their time, patience and dedication. Also, thank you to Alicia Camacho, the cantaora from Buenaventura.

Finally, I am very grateful to my family and friends in Bogota and Miami. To my mother, Trinidad Castellanos, and my sisters, Claudia and Monica. I wish to thank Seth and Dorcas, Pedro Delgado, María Eugenia, Radek Valero, Andrés, Javier and John, for their friendship.

To Paolo Vignolo, professor at the Department of History of the National University of Colombia: Thanks for the final push. 


\section{ABSTRACT OF THE THESIS \\ RELIGION AND ETHNICITY AMONG AFRO-COLOMBIAN MUSLIMS IN BUENAVENTURA (COLOMBIA)}

by

\section{Diego Giovanni Castellanos}

Florida International University, 2018

Miami, Florida

\section{Professor Ana Maria Bidegain, Major Professor}

The purpose of this thesis is to analyze the way in which religious beliefs and practices are instrumentalized by a Muslim community in order to strengthen AfroColombian ethnic identity, in an urban context of social exclusion. The study aims to examine the relationship between ethnicity and religion, and the role they play in the process of identity construction, particularly the way in which religious concepts and behaviors can be used to fortify ethnic identity. Another aim of this research is to describe and understand the processes of social change in an ethnic-religious minority and, as a final goal, to analyze the history of the Afro-Colombian Muslim community of Buenaventura. The thesis is based on fieldwork, which includes observation activities and interviews with members of the Muslim community in Buenaventura. A total of 21 participants between the ages of 18 and 72 are included in this study, all of them of AfroColombian origin.

It is clear that the religious conversion of Afro-Colombians to Islam took place within the complex socio-political context of the Colombian conflict. To be sure, the adoption of this new religious perspective did not evolve in an isolated manner, rather, it 
transformed the identity of the community by strengthening the value of ethnic differences in a place of segregation. In this way, this thesis analyzes the role of religion as an important element in the construction of ethnic identity. Departing from this paradigm, we will look into some theological concepts, such as the Islamic jurisprudence and rituals, which have been reworked, in order to accommodate local aspirations for social mobility and ethnic differentiation. It is important to keep in mind, however, that this cultural negotiation happens at the margins of the dominant society, which negatively views Afro-Colombian minorities, or simply ignores them.

Other findings include the identification of key moments of the historical development of the community; the analysis of the processes of conversion to Islam in this population; and the description of the organization, institutionalization, and hierarchy in the community in accordance with the changes from the Islamic perspective they have developed through its five-decade history. 


\section{TABLE OF CONTENTS}

CHAPTER

PAGE

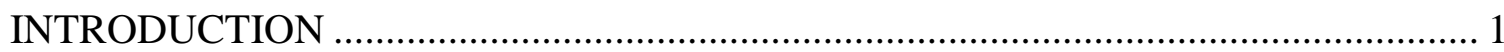

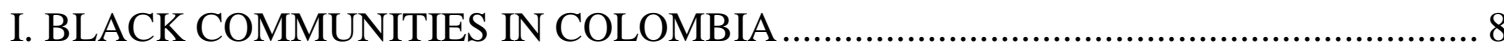

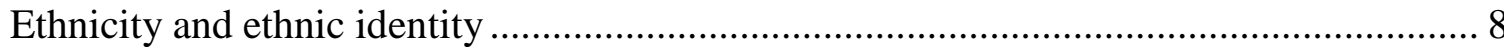

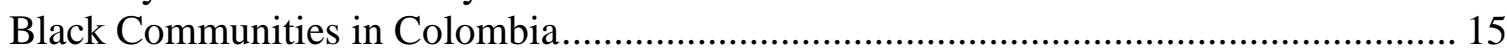

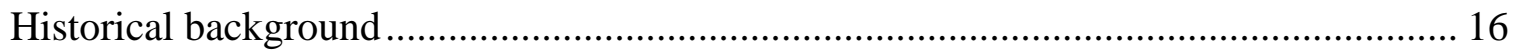

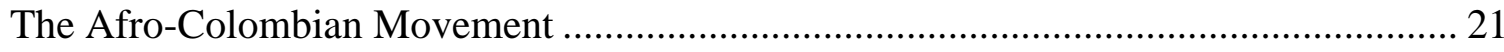

Establishment of the Afro-Colombian ethnic identity ................................................... 25

Constitutive elements of the Afro-Colombian identity................................................. 29

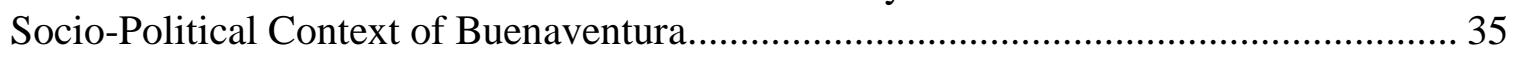

II. ANTECEDENTS OF A MUSLIM COMMUNITY …………………....................... 39

Muslim Communities in Colombia............................................................................ 42

History of Buenaventura Muslim Community …………............................................ 47

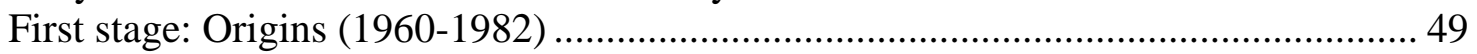

Second stage: Crisis and search of new models (1982-1988) ...................................... 55

Third stage: Adoption of Shi'ism (1989-2000) ………........................................ 58

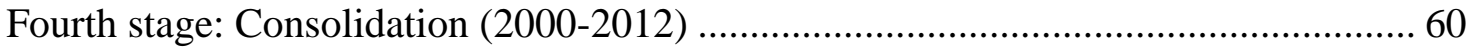

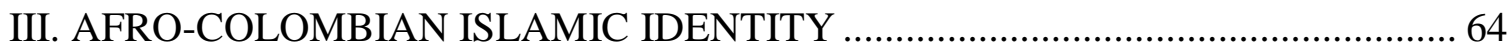

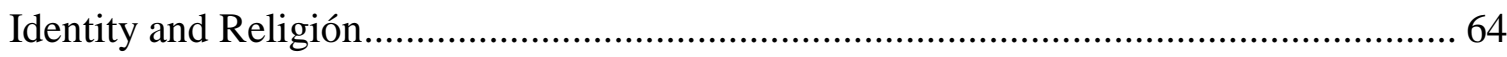

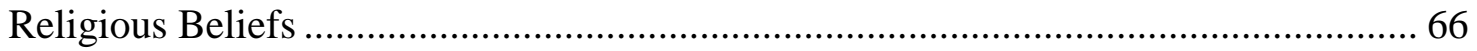

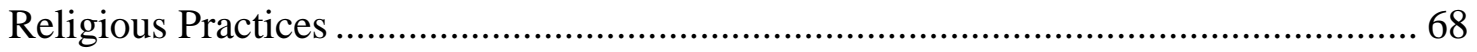

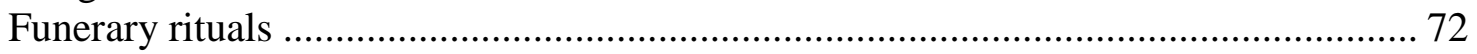

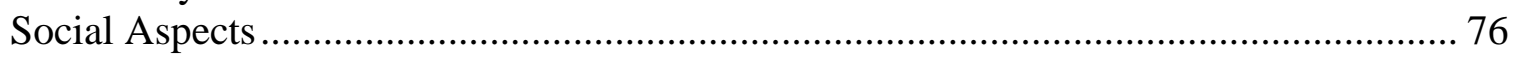

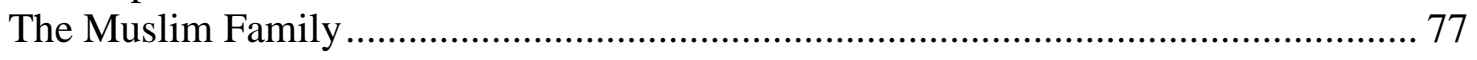

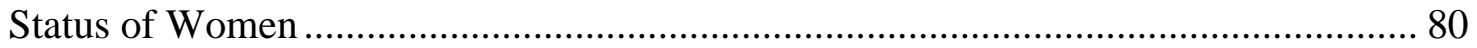

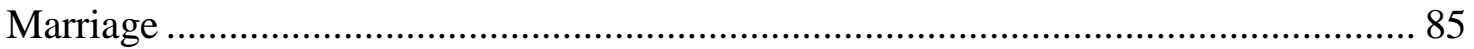

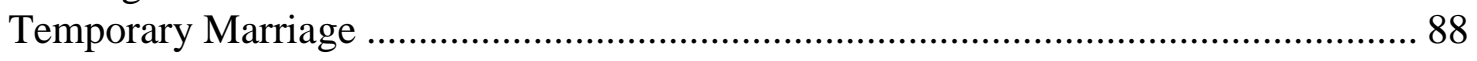

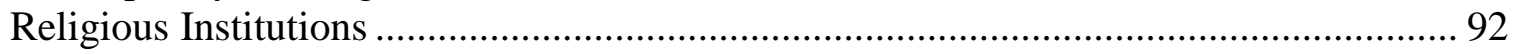

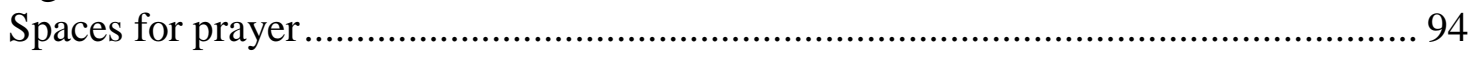

Religious leaders ……................................................................................. 99

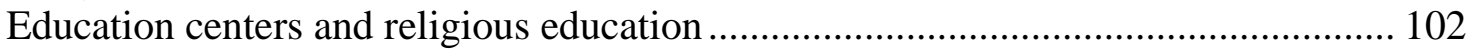

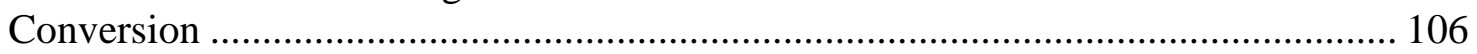

Interreligious and inter-institutional relations ........................................................ 108

IV. RELIGION AND ETHNICITY IN BUENAVENTURA ………………….......... 110

Black Communities in Buenaventura .................................................................... 111

Religious Adaptations and Transformations............................................................. 116

Muslims as a Black Community ………………………......................................... 122 


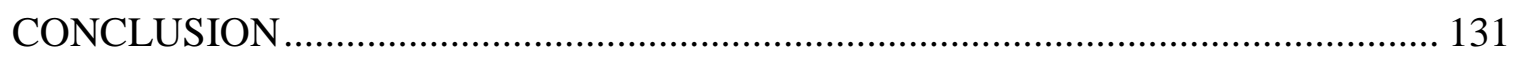

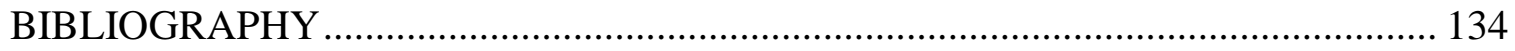




\section{INTRODUCTION}

The purpose of this thesis is to analyze the relationship between ethnicity and religion within the Muslim community of Buenaventura. In Colombia, a predominantly Christian country, Muslims are a religious minority of relatively recent appearance. Despite their small numbers, however, the Muslim community shows a wide range of ethnic identities and religious interpretations. Interestingly, while most of the Muslim population in Colombia is Sunni, in the case of Buenaventura, the Muslim population is mainly Shi'ite and Afro-Colombian.

The Muslim community of Buenaventura can be described as a group of Colombians that, for over half a century has used Islam as a way to find and define a place in society. The decision to convert to Islam has sometimes meant new opportunities but, more frequently, has meant new barriers, especially in a predominantly Christian society.

In Colombia, people of African descent have historically been marginalized. In this context, the conversion to Islam of a group of Afro-Colombians in the sixties of the last century, should not be seen as a marginal story, but as an event that demands a careful analysis in order to clarify the social and personal circumstances that placed the idea of conversion to Islam as an alternative in the first place.

Colombia has a large population with African roots (21\%). They are the descendants of enslaved people from Africa, brought during the period of Spanish rule in the Americas. Many of them are located in the western region of the country, along the Pacific coast. After the abolition of slavery in 1851, they organized in small communities on the banks of rivers or near the sea, where they were able to continue many of their 
traditional values and practices. The preservation of their African culture, however, was under constant threat of being absorbed by the dominant Christian context. Also, the introduction of modernity and the world economy into Colombia implied changes and challenges that affected not just the Afro-Communities, but the entire population throughout the twentieth century. One of the major consequences was the constant migration of people from rural to urban areas, leading to problems of adaptation and assimilation in the big cities. From the Afro-Colombian perspective, they suffered a double jeopardy, first as displaced people, and second because of racism. To be sure, the mainstream culture, following the national discourse imposed by European-descended elites, has systematically marginalized the African experience and cultural contributions.

For this reason, Afro-Colombians who traveled to the cities needed to develop alternative discourses that gave support to their identity and customs. Initially, they kept their traditional worldview in which kinship and territory were considered vital to social organization. However, in the second half of the twentieth century, Afro-Colombians began to enhance their ability to integrate into the social structure of Colombian cities. In this new context, traditional values did not seem so useful and attractive in their efforts to adapt. This opened the door for the re-elaboration of their ethnic identity. In this way, in the process of dealing with the problems of modern city-life for the working class, AfroColombians redefined their identity, also inspired by the struggles of minorities of African descent in other parts of the world.

In the late sixties, a small group of young Afro-Colombian leaders became interested in the ideas of the Nation of Islam. This group was successful in establishing a modest organization in the seventies and was the basis of what later became the first 
legally recognized Muslim community in Colombia. During its first twenty years of existence, the community was identified with the ideology of the Nation of Islam. It wasn't until the eighties that tensions began to emerge within the community, leading to the temporary adoption of Sunni Islam. However, in the early nineties, Shi' ite Islam became the official branch of the group until this very day.

The Muslim community of Buenaventura is composed of at least 600 individuals, of which about 350 are located in that town, while others are based in Cali, the regional capital city.

\section{The research}

This thesis analyzes the way in which religious beliefs and practices are used by the members of a Muslim community in order to strengthen their ethnic identity in a context of social exclusion. Based on the consideration of religion as a cultural dimension $^{1}$, our aim is to explain the conversion of a group of Afro-Colombians to Islam as a mechanism to produce an alternative discourse of inclusion and recognition within an important world religion. This study also seeks to describe and understand the processes of social change. As a final goal, we will present an interpretation of the history of the Afro-Colombian Muslim community of Buenaventura.

In that sense, this thesis will explore the relation between ethnicity and religion, namely, the role of religion in shaping and even strengthening ethnic identity. Theoretical approaches are taken from the work of Fredrik Barth, Steve Fenton, Ernesto Garcia

\section{Canclini, Clifford Geertz and Nancy Ammerman.}

\footnotetext{
${ }^{1}$ I took Clifford Geertz's definition of religion, as "a system of symbols which acts to establish powerful, pervasive and long-lasting moods and motivations in men by formulating conceptions of a general order of existence and clothing these conceptions with such an aura of factuality that the moods and motivations seem uniquely realistic" (Geertz 1973: 90).
} 
The main question the thesis aims to answer is: What is the relation between ethnic identity and religious life in the Afro-Colombian Muslim community? Other important questions to consider are: Which were the causes of their conversion to Islam? What does it mean for this cohort of Muslims to be Afro-Colombian? How have they adapted Islam to local realities?

The hypothesis is that in the Muslim community of Buenaventura, religious identity has been taken as a vehicle for the transmission of ethnic values. In this way, desires for some kind of social vindication and the construction of Afro-Colombian identity have paved the way toward the reinterpretation and adaption of the ritualistic, theological, and ideological structure of Islam, as it exists in Shi'ism and the Nation of Islam.

Since no secondary sources about Buenaventura's Muslim community exist, the main information was collected during two periods of fieldwork: the first in April, and the second one in May and June of 2011, with the support of a grant awarded by the Latin American and Caribbean Center at Florida International University. The ethnographic work included activities of observation, interviews, and attendance at mosques and other meeting places. While interviews had a basic structure, each was flexible, according to the narrative priorities of each person or the group. The total number of people interviewed was 21 and included a vast range of perspectives, from religious leaders to longstanding members of the community. The activities of observation included the participation in Friday prayers and other activities conducted in the mosque, as well as in the Muslim School. Some life stories were collected in order to identify long-term trends and to reconstruct the history of the community. Another important source of information 
was the homilies and other speeches of Sheikh Munir Valencia Potes, which were recorded by the Mosque Council. There is an almost total absence of written primary sources because of the precariousness of the early days of the community.

\section{Background}

Due to the Catholic predominance in society and institutions, studies on the presence of religious minorities in Latin America are relatively new. Consequently, the great religious diversity of the region was not the object of research until recent times. However, the arrival of Protestantism and the proliferation of new religious movements, as well as a wave of democratization in the last decades, permitted religious and social minorities to vindicate their rights in the public sphere.

In this vein, studies about Islam and the presence of Muslim communities in Latin America are particularly a new field of academic interest; in fact, local scholars only began conducting serious research in the late nineties. However, it was not until 2010 that some general studies in Spanish and Portuguese began to appear, giving an account of the characteristics and peculiarities of these communities. English sources are even scarcer. There is, indeed, a research initiative about Islam in Latin America, coordinated by the Center for the Study of Latin America and the Caribbean of Florida International University in 2009 under the direction of Maria del Mar Logroño. Their research culminated in 2015 with a text titled Crescent over Another Horizon: Islam in Latin America, the Caribbean, and Latino USA. Author Aisha Khan published in 2004 Callaloo Nation: Metaphors of Race and Religious Identity among South Asians in Trinidad, and edited Islam and the Americas in 2015. Another text to consider is The Construction of Muslim Identities in Contemporary Brazil" published by Maria Cristina 
de Castro in 2013. To these studies we could add some academic articles about the region, but, again, the topic remains almost nonexistent in the case of Islam in Colombia.

In contrast, studies about ethnicity in Latin America have been more numerous; however, in the case of Colombia, these studies tend to focus more on indigenous and black identities, and even on the problem of drug trafficking and the armed conflict. Consequently, studies about the relationship between ethnicity and religion in Colombia, and particularly about a Muslim minority, have not been published in the English language, and in Spanish, it is still not a usual topic.

Regarding Islam and conversion to Islam in Colombia there are some academic publications. In the book Identidad y Minorias Musulmanas en Colombia (2009), Maria del Rosario Garcia offers a historical and legislative context for understanding the emergence of Muslim minorities in the country. The book Islam en Bogota, Presencia Inicial y Diversidad, by Diego Giovanni Castellanos (2010), presents an overview of the coming of Islam to Colombia and its presence in major cities.

By contrast, the literature on people of African descent in Colombia is wide, although of different qualities. This thesis uses, among other secondary sources, the book of Gwendolyn Midlo (2005) Restoring the Links: Slavery and African Ethnicities in the Americas. Among the texts relevant to provide support for the contextualization of this study are the two texts of Luis Castillo (2009) Etnicidad y Nación: El Desafío de la Diversidad en Colombia; and Visiones de Espiritualidad Afrocolombiana by Sergio Mosquera (2000). Other studies used were the compilation book 150 Años de la Abolición de la Esclavitud en Colombia: Desde la marginalidad a la construcción de la Nación (2003), and (regarding the religious and spiritual dimension of African 
descendants) Velorios y Santos Vivos: Comunidades Negras, Afrocolombianas, Raizales y Palenqueras, both published in 2008 by the National Museum of Colombia. Regarding the port of Buenaventura and socio-economic problems, there are many technical reports published by government institutions and NGOs, among which is the text of Gerson Perez (2007) Historia, geografía y puerto como determinantes de la situación social de Buenaventura.

There is an extensive literature about the Nation of Islam, Malcolm X, and generally about Black Islam in America, but this thesis uses The Cambridge Companion to Malcolm X (2010), edited by Robert Terrill; West of Allah: the penetration of Islam in the West (1995) by Gilles Keppel; and Black Pilgrimage to Islam (2002) by Robert Dannin. 


\section{BLACK COMMUNITIES IN COLOMBIA}

"I think that term ethnicity is rather a term of white people, to make a difference from others. Because when they talk about ethnicity, they do not speak about white ethnicity, but about indigenous ethnicity. About black ethnicity..." (Pardo 2001: 64).

One of the main characteristics of the Muslim community of Buenaventura is that it almost entirely consists of African descendant people. As a result, they are identified, both by Muslims themselves and people and institutions outside them, by their ethnicity. Also, as is the case with other ethnic minorities in Colombia, physical characteristics are interpreted as evidence of belonging to a particular ethnic group, with a distinct culture. Indeed, in Colombia, while external attributes do not necessarily imply cultural differentiation, they don't exclude it. Therefore, in this study, we presume that the formation process of an Afro-Colombian Muslim community involves a certain negotiation of identity.

This is not unusual in the history of Islam, and religions in general. Although Islam is a set of beliefs and practices that promotes a sense of universality, Muslim character is based on local cultures by interacting with other identities, interests, and perspectives.

\section{Ethnicity and ethnic identity}

According to John Stone, "ethnicity" is a category of social organization characterized for its focus on group membership (Kuper 2005: 260). This affiliation is based on the idea of having common historical origins, and may also include a culture, a religion, or a common language. This aspect of ethnicity is also mentioned by Max 
Weber, when he says that ethnic groups are "human groups (other than kinship groups) which cherish a belief in their common origins of such a kind that it provides a basis for the creation of a community (Weber 1968: 389)." However, other forms of social organization share this idea of a common past. One of these is the notion of "race," which is based on the idea of the existence of a common biological component, manifested by physical characteristics. Other categories, such as "nation," are not only based on origin, but also on idealized belonging to a common political structure. As Stone argued, such concepts are sometimes related. An example of such interaction is observed in Weber when he affirms: "a nation is a political extension of the ethnic community because its members and leadership searched for a unique political structure by establishing an independent state" (Stone 1995: 4).

In addition to relying on the idea of a past and a common culture, "ethnic" social organizations are characterized by generating strong identities that involve the establishment of limits. In this regard, one of the most influential approaches has been proposed by Fredrik Barth, who emphasizes the processes by which ethnic groups define themselves through actions of inclusion and exclusion. According to Barth, an ethnic group can be anthropologically defined according to four characteristics:

1. It is largely biologically self-perpetuating.

2. Shares fundamental cultural values.

3. Integrates a field of communication and interaction.

4. It has some members who identify themselves, and are identified by others, as a category distinguishable from other categories of the same order (Barth 1969: 11). 
Of these four aspects, Barth believes that identity is the most relevant to the definition of "ethnic group". However, that definition needs to be expanded to account for the current reality of ethnic minorities in the contemporary world, which have had to adapt to exist within national states. For this reason, according to Steve Fenton, "ethnicity" refers to ethnic communities of common descent and culture, but with three specific characteristics:

1. That the group is a kind of sub-set within a nation state,

2. That the point of reference of difference is typically cultural rather than of physical appearance, and

3. Often that the group referred to is "other" (foreign, exotic, minority), to some majority who are presumed not to be "ethnic" (Fenton 2005; 23).

This approach is particularly useful for the analysis of black populations in Colombia, not just because of their origin, but because they are considered an ethnic group by the "not-ethnic" mestizo-majority society. However, the second point of Fenton's definition does not fit as well for the case studied here, since Afro-Descendants in Colombia have had to assume a collective identity based in their physical appearance, not only by choice, but also due to coercion by the Mestizo society.

Such variations of the original definition are necessary because, as Fenton says, there is not a single phenomenon that can be called "ethnicity." Actually, as we see, there is a set of public and private identities which revolve around ideas of descent and culture (Fenton 2005: 179). On the other hand, the contexts in which ethnicities work are crucial to the understanding of the strength such ideas have within a specific social reality, as 
well as the role they play in it. This last point is particularly important because the political actions and economic interests tend to affect the way in which ethnicity manifests. This is because ethnicity is originated, processed and changes within specific social settings, leading to frequent manipulation.

According to Rupert Brown, identity refers, in a primary sense, to a personal definition of an individual in relation to others (Kuper 2005: 373). However, that definition takes place in terms of the subject belonging to different groups, leading to a personal experience which depends largely on the point of view of the social group. Thus, according to Stephen Lawler, the idea of difference develops from a personal experience, but at the same time from the recognition of common characteristics that are shared with other individuals.

Because those common characteristics refer to physical realities, language, religious beliefs, biological descent, political views, etc., each subject is recognized as part of different groups and, accordingly, can participate in the development of different identities. This does not mean that identities are cumulative, but each one works in a specific context and impacts the others, overlapping and sometimes contradicting each other. For this reason, we should assume that identities are interactive and mutually constitutive, while dynamic. In the studied case, religious identity and ethnic or national identity are not only related, but sometimes complement or contradict each other.

As noted earlier, although there is some form of ethnic identity, it does not necessarily imply that ethnicity constitutes the most important social reference, or the main engine of mobilization. Indeed, when a given problem is analyzed, it is not enough that there is an ethnic identity in the group studied to consider that ethnicity plays a 
decisive role in the issue. For that to happen, the researcher must ensure that either ethnicity is a motivation for collective action, or is seen as the main framework within which certain social organizations act. As is quite evident in the case analyzed here, the birth of a religious community (of Muslims) in Buenaventura, and the subsequent changes that took place within it, were due to the need to articulate the basis for the definition of ethnicity.

In the case of Buenaventura Muslims, once their ethnic and religious identities were established, such identities went beyond simple identification purposes, but gave way to mobilization strategies. This happened in two ways: first, actions reinterpreting traditional myths and symbols according to the new frameworks were initiated; second, action agendas were developed within the new community in pursuit of political and economic, private and community interests, which led them to become agents of change impacting the environments in which they operate.

To understand the way in which local, national and global social realities are articulated in this study, we must consider the existence of relations between the global and the local. This situation has resulted in what has come to be known as "hybrid" or syncretic identities, where cultural elements of different origins are combined. While the exact nature and meaning of these hybridizations are under discussion, as Canclini says, it seems that this type of composite identities is a relatively permanent global social process (Canclini 1990: 36). This is particularly relevant in the case of ethnic and religious minorities, and for observing the role of power relations. As will be seen, the last not only have an impact through political and educational institutions, but in itself explain the emergence of new identities and of the discourses in which they are based. 
Considering that the processes of identity construction are dynamic, fluid and changing in time and space (Pardo 2001: 123), it is difficult to think the current AfroColombian ethnicity as surviving from the days of slavery, or even further back from the African continent. As stated above, it is clear that politics are infused in any process of identity construction and this, as we shall see, is true for the case of ethnicity and that of religion, in the case of the Muslim community studied. For these reasons, we must pay attention to the emergence, establishment, and development of social movements of black people in Colombia, and the way in which they were involved in the construction and articulation of new political identities, to understand the interaction between ethnicity and religion. As a result, the interaction between ethnic and religious identity becomes visible, in the way in which individual, family, and group interests are constituted, in relation with the socio-political processes lead by the Colombian state and its institutions. To understand the context in which this kind of phenomenon occurred, one must consider the profound social changes affecting the Afro-Colombian immigrants to Buenaventura city during the second half of the twentieth century. At the same time, it is also necessary to consider the discourses and actions motivated by the elites ruling the nation-state.

According to Clifford Geertz (1973: 241), in new states people first establish relationships with other people whom they think are of the same "race", with whom they have kinship, with those who speak the same language, or those with whom there is a sense of past and future, based on a shared territory, religion, or customs. This approach illustrates the manner in which the identity of Colombian society was built on geographical and cultural bases after independence, and transmitted by the education system. 
Indeed, in Colombia, most of the population lives in the large cities of the Andes or in the Atlantic coast, and most of the local elites descend from Spanish immigrants. It was on this image of the common past and on the aspiration to create a biological or cultural "white" society, that the first idea of nation was established in the nineteenth century. Because such elites possessed a monopoly over the education system, that paradigm prevailed, in opposition to the mestizo, indigenous and black realities, which were suppressed.

According to Myriam Ximeno (Silva 1994: 74), the nation-state discourse in Colombia focused on the idea of national identity in the second half of the twentieth century. For the promotion of this identity, each Colombian region was highlighted: the Andean plateau, the Antioquia province, the Atlantic coast, the eastern plains, the Amazon forest, and the Pacific Coast. To each region, distinctive features were attributed, not always positive, and often served as "natural" explanations of social phenomena. According to this discourse, biological, racial, climatic, and geographic factors characterize each region, and served to explain the regional position, prominent or marginal within the national order.

Thus, ideas about races and their classification in the social stratification, in good part, a Spanish colonial legacy, come to be related to each region. According to this view, the most backward regions were those that had suffered less miscegenation, that is, the population was less "white". Those were the regions where black and indigenous populations were located. The identity by regional origin simultaneously has had a racial meaning, so that race was "regionalized." It was only in recent decades that social mobilization, related to the creation of a new political constitution in Colombia, led to the 
recognition of cultural diversity. As will be seen below, one of the results of that process was the creation of an Afro-Colombian identity by black communities.

\section{Black Communities in Colombia}

Luis Castillo (2009 64) defines "Afro-Colombians" as the descendants of black Africans who were brought as slaves to New Granada (current Colombia), during the Spanish Colonial Period. As this population came from different regions and societies in Africa, the question arises if the mere fact of one's ancestors coming from that continent is a sufficient condition to consider one a member of a single ethnic group. However, the term "Afro-Colombian" is currently accepted in reference to a real population.

In itself, the term "Afro-Colombian" appears in the seventies, based on "African American", a term authored by anthropologist Melville Herkovits, and proposed in the sixties by social movements in the United States to refer to the descendants of African populations that arrived from Africa to America as slaves (Suarez 2010: 2494).

Oscar Almario indicates that, by the end of the eighties, many riverside communities in a state of relative isolation did not retain memories of the period in which their ancestors were slaves; although, it was common to use the word "free" to refer to themselves (Almario 2009: 80). Black communities in Colombia do not necessarily keep the memory of the African past and slavery in their collective memory. Apparently, many people were stunned, shocked and saddened, when Catholic missionaries in the eighties described their past to them (Pardo 2001: 235). Only black populations who remained in urban areas, or in areas under the influence of urban centers, held a memory of slavery. In part because of the discrimination they suffered by the mestizo majority. But in the 
isolated areas, where the black skin was a characteristic of the entire population, the memories of slavery were rapidly forgotten.

In fact, black ethnic identities are linked to the territory, and in that sense, to the existence of local cultures. Because of this, Jaime Arocha (Various 2008: 17) asserts that under the homogenization that implies the definition of an "Afro-Colombian population," there is a diversity that includes different African roots and subsequent developments and differentiation specific to each community. As examples of this diversity are cited the Raizales, Palenqueros of San Balisio and San José de Uré, the Sanpacheros of the Atrato and San Juan rivers, Resurgentes and Libres in the Pacific region; miners and farmers of the Colombian Southern Pacific; and Lucumíes, Angolas, Carabalis of northern Cauca.

Indeed, the historiography of the African past, enslavement, and arrival at each specific territory plays an important role in the discourse of the Afro-Colombian organizations. It is well known that the black movement for the recognition of rights and opportunities is a recent, predominantly urban, largely academic phenomenon. However, the success achieved by the term makes it possible to adopt "Afro-Colombians" as a useful category in this thesis.

\section{Historical background}

Undeniably, the current Afro-Colombians are mostly descendants of enslaved Africans, brought as merchandise to be sold to colonial America and, in this specific case, to New Granada (current Colombia). Although the African ancestors did not constitute an ethnically homogeneous group, the slavery condition and the process of Christianization controlled by the ruling elites, led them to generate a new kind of identity in the Americas. 
Slavery, understood as a kind of social relationship under which a person is treated as property and forced to work, was not a purely European characteristic. Societies on all continents and at different times have practiced different forms of slavery. In the case of Africa and the Americas, the two continents had known forms of servitude and subjection before the arrival of Europeans. However, in these continents it was a smaller institution, often of domestic character, and although part of the social daily life, it did not form the basis of the economic system.

It was with the arrival of the Portuguese to sub-Saharan Africa, in the early fifteenth century, that a new stage in the development of slavery on the continent began, in terms of the intensity of trade, the places of origin of slaves, and the tasks to which they were assigned (Klein 1986: 13). The use of slaves was due to several factors that hindered or precluded the use of indigenous labor in various regions of the Americas. So while in Mexico and Peru colonial slaves were more of a luxury, intended for domestic or urban spaces and tasks; in Brazil, the Caribbean and the United States, slaves were the foundation of economic life.

Taken together, the forced migration of Africans to America was a phenomenon that affected the historical development of societies in both continents. According to Herbert Klein, in the two and a half centuries that slave trafficking lasted, about 10 to 15 million Africans crossed the Atlantic, and between 1 and 2 million more lost their lives during the journey (1986: 140). The initial slave economies were located in territories ruled by Spain and Portugal, but in the Spanish case, this role was only during the sixteenth century. From the seventeenth century the demand for slaves began to wane. In the eighteenth century the demand for slaves started again to grow in the Spanish 
colonies due to the revival of industry, after the Bourbon reforms. However, after the wars of independence that led to the birth of new nations in Latin America, the demand for slaves almost came to an end in these territories. Only Cuba and Santo Domingo maintained a growing demand for slaves until the late nineteenth century.

Europeans did not know much about African societies, and a common practice was to mix their slaves from as many different cultures as possible, in order to divide them and force them to communicate through the language of the dominant white elite (Klein 1986: 146). Despite this, their marginal status in many places allowed them to create particular traditions and cultures in the New World, for which they took elements of African, European and American origin. This culture possessed African elements, adapted within the framework of the dominant culture. In addition, many of the social institutions in which their worldview was based disappeared in the Americas. Variants of European Christianity became the dominant religion, albeit with cases of syncretism. In many places the slaves developed behaviors and beliefs that were unique to them, seeking to create an alternative version offered by the dominant culture to justify and rationalize their domination (Klein 1986: 166).

In the case of New Granada, the existence of relatively large sedentary indigenous communities allowed the establishment of urban centers in the mountains of the interior, in the valleys and along the Atlantic Coast. However, slave labor was considered an option when some resources were in inaccessible places or in which the indigenous populations were scarce and less compliant.

Among the resources for which slave labor was used, gold had a predominant role in the case of New Granada. Gold was exploited since the mid-sixteenth century in the 
mountains in the north of Tunja, in areas near Popayan and Antioquia. The exploitation of mines began in the Pacific region and, by 1782 , the number of slaves was 7,000 , which represented $13 \%$ of the slave population of the Viceroyalty of New Granada (Klein 1986: 84). According to Adriana Maya, the Africans who arrived to New Granada were mainly of Yolofa culture. Since the first half of the seventeenth century and during the eighteenth century Ewe, Akan, Popo and Ibo people arrived, too (Maya 2000: 36). Many of them were assigned to mining work near Cartagena, but more importantly was their presence at mining sites of the valley of the Cauca and Magdalena rivers. Likewise, they were used on farms and river transport.

With regards to religion, syncretism was the dominant trend, but it is clear that fewer African cultural elements survived among slaves of New Granada when compared with those of Brazil and the Caribbean (Klein 1986: 169). It was more frequently the formation of a subculture within Catholic Christianity, which allowed them to integrate and differentiate from the dominant culture as they needed.

However, as in other parts of the continent, the slaves, no matter how relatively better or worse their condition, expressed a general state hostility towards the system. For this reason, the slaves engaged in many forms of resistance, through which they sought to evade the attempts made to physically, mentally, and spiritually control them. Thus, maroons were common; as well as the practice of rituals, dances, and songs as a symbol of resistance; and even reworking of religiosity in order to include within the dominant discourse, the perspective of the subjugated.

Once the wars of independence ended, the new republic planned the gradual release of all slaves. The project began with the enactment of Law 21 of 1821, known as 
of "Freedom of Bellies". This Law involved the release of all the children of slaves that were born from that date. Subsequently, Decree 28 of 1827 created the Directorate of Manumission, as a prelude to the final enactment of Law 21 of 1851, which determined the abolition of slavery. Thus, from 54,000 slaves that existed in Colombia at the end of the colonial period, to 1851, the year of the final emancipation of all slaves, there were only 16,000 slaves (Klein 1986: 251).

After independence, and after the end of slavery, the lives of African descendants were marked by marginalization and exclusion. One of the main reasons was the fact that, in the Colombian Pacific region, the former slaves were located in remote areas with virtually no state investment. This situation, on the other hand, allowed them to develop and maintain distinctive cultures for a long time.

In the present day, the number of Afro-Colombians is estimated to be seven million people, which constitutes about $15 \%$ of the Colombian population (Roux 2010). Of them, the majority live in the Valle del Cauca department, which accounts for a quarter of the total black population. Buenaventura, located in Valle del Cauca, is the city with the highest percentage of Afro-Colombians with 300,000 African descendants, which is $85 \%$ of the population (Roux 2010: 10).

Despite their number, the black population remains a group with high levels of poverty and exclusion. While in $200945.5 \%$ of people living in Colombia were under the poverty line, $53 \%$ of Afro-Colombians were in that condition. Meanwhile, people of African descent face disadvantages in accessing the social security system, and have higher rates of infant and maternal mortality. 


\section{The Afro-Colombian Movement}

In order to understand the circumstances that led to the rise of the Muslim community, it is necessary to consider the social struggles of black people in Colombia. Although the Muslims emerged as a well-defined group, it is not possible to fully understand their origin and transformations without considering the dynamics that affected Afro-Colombian population when they migrated to the main cities. Many of the changes and challenges that subsequently affected the community are better understood by relating them to the evolution and transformation of the black movement in Colombia. In effect, the study of the ideas of Malcolm X and other black American thinkers was common practice among various Afro-Colombian movements in the sixties and seventies.

Historically, most of the black population participated only sporadically in political life, because of the level of exclusion and marginalization. Except for the exceptional case of political leaders during the civil wars that took place in Colombia repeatedly after independence, most black people did not take an active role toward exercising their civil rights. They used to participate in elections or to be affiliated with the Liberal and Conservative political parties, which prevailed during most of Colombian political history. In fact, because the Law of manumission of slaves took place during the government of Jose Hilario Lopez, a liberal president, most of the black population was identified, either explicitly or implicitly, as being politically liberal.

In the seventies, thanks to an increasing, though still limited, access to higher education, the first black student organizations representing exclusively the interests of their communities emerged. That was the beginning of a wider recognition of a common 
Afro-Colombian ethnic identity. Some of the most important movements during this initial period were the establishment of the Center for Research in Black Culture (CIDCUN), the Colombian Folkloric Research Foundation, and the Center of Studies "Franz Fanon". But the organization that would acquire more importance and continuity, until it became a political project was the Soweto Studies Center, which later became the "CIMARRÓN" movement (Castillo 2009: 179).

In the specific case of this group, its origins date back to 1976, when a group of students from the Technological University of Pereira, originally from the Pacific region, united under the leadership of Juan de Dios Mosquera, then a student of sociology. Influenced by the struggle for civil rights in the United States, the group claimed equality for black Colombians. The main objective was the integration of black people, access to education, health, and work. By conducting development projects for black communities, they wanted to improve their quality of life. In doing so, the group began to use a discourse involving the rescue and recognition of the Afro-Colombian history, culture, and ethnic identity.

Many of these movements were initially led by charismatic leaders, and it was only over time that they were structured as established organizations. In the case of the Cimarron Movement, Juan de Dios Mosquera exerted an influence that extended to the Colombian Atlantic and Pacific coasts, as well as to black communities in northern Cauca. His main impact was among young people, usually university students. His strategy included the discussion of the ideas of black writers like Martin Luther King, Jr. and Malcolm X, as well as denouncing the situation of marginalization black people suffered in Colombia. While Cimarron Movement was especially important in the 
reunion and training of black leaders, over time it oriented toward a single leader structure. This situation eventually caused the withdrawal of many young leaders, which subsequently weakened the organization.

Besides the Cimarron group, other groups began to work from multiple perspectives, influences, and purposes; with the common objective of the recognition of people of African descent. Some affiliations included Marxist and other leftist groups, Catholic (and even Muslim) organizations, and peasant associations.

An important influence was exerted by the Catholic Church, although not as an institutional policy. By the end of the sixties, under the premises of Liberation Theology, individuals and groups including the "Pastoral ecclesial" (Ecclesiastical Ministry) and "Comunidades Eclesiales de Base" (Basic Ecclesial Communities), emphasized the uniqueness of the black movement and denounced the state of marginalization of black people. The most recognized leader in this process was Gerardo Valencia Cano, called "Obispo Rojo (Red Bishop) de Buenaventura". He created the Golconda group ${ }^{2}$ and affirmed in his preaching that black people were innately neither farmers nor workers, and therefore deserving of different treatment from the rest of Colombian society and institutions. Gerardo Valencia created the center Matias Mulumba, with the purpose of educating leaders through all the Colombian Pacific. One of the most important results of his work and thought were the groups that gave rise to the Basic Ecclesial Communities, of which later would come out some of the leaders of the Black Communities Party. This process was reinforced by the Afro-American Pastoral, which under the banner of

\footnotetext{
${ }^{2}$ Golconda was an association of Colombian Catholic clergy who decided to work together in the late $60 \mathrm{~s}$ and early 70s under the premises of Liberation Theology.
} 
liberation theology, evangelized among the then-so-called Afro-Descendants, as part of their commitment to the poor.

In the sixties, a multitude of leftist-Marxist groups also emerged, which caught the attention of many young people. Among these was the workers' and revolutionary movement MOIR. Although it brought together many Afro-Colombians interested in social struggles, it soon became clear that leftist groups did not represent the agenda of black groups. However, those organizations provided the opportunity for political and management education for young leaders, including some of the founding members of the Muslim community of Buenaventura. Another significant movement was started by black farmers in the Choco department, which gave birth to the Black Peasantry Association of Atrato River. The importance of this movement is that it was the first Afro-Colombian peasant organization to obtain recognition of the right over their territories, in 1988. This move was preceded by the mobilization caused by the promulgation of Law 2 of 1959, which declared much of the Colombian Pacific region as wastelands, i.e., empty uninhabited spaces available to the State.

Following this Act, the Colombian state granted land exploitation rights for mining, fishing, and timber to large companies, which led to a deterioration of the living conditions of the black population of the area. In response, the local community organized the Black Peasantry Association of Atrato River (ACIA), with the support of the Basic Ecclesial Communities (Pardo 2001: 235). In 1989, the ACIA succeeded in obtaining from the Colombian State the managing rights of the area in which the community had lived for centuries. This was considered a victory on the part of different black and indigenous organizations. Other important examples of mobilization of the 
black communities, although not as involved in the issue treated here, were the Palenque de San Basilio, on the Atlantic Coast, and the black centers in northern Cauca.

The great opportunity for the movement of black communities was in 1991, when Colombia convened a National Constituent Assembly. In this political environment, many social sectors of different origins were seeking to develop a new constitution for the country, founded on more inclusive bases.

With the promulgation of the transitional decree 55 of the National Constituent Assembly, the category of "Comunidades Negras" (black communities) was introduced in the legislation. The law defined Black Communities based on traditional practices of production, and the ancestral occupation of the banks of the great rivers of the Pacific Coast (Castillo 2008: 170). However, this was only the prelude to the enactment of Law 70 of 1993, by which the Colombian State recognized the right to collective ownership of land to black communities, a particular cultural identity, and their rights of being protected as ethnic groups. The Law also promoted their economic and social development, in order to ensure these communities equal opportunities with the rest of the Colombian population (Wabgou 2012: 55).

\section{Establishment of the Afro-Colombian ethnic identity}

The Colombian black movement, which took the various forms as described above and which ultimately achieved formal recognition in the form of the rights enumerated in the 1991 Constitution, reinvented, in the process, Colombian black ethnic identity. This process not only involved black organizations, but intellectuals and state institutions. They used historical, geographical, and biological data, as well as oral traditions, to create an idea of "Afro-Colombian Ethnicity". Once this ethnic change was 
recognized by the Colombian State, the government produced the institutional instruments to reinforce and disseminate it.

Perhaps the most significant attribute was the very idea that all Colombian Black Communities have some common ethnic identity. As stated above, although a sense of identity among African descendants existed from the colonial period as a product of social stratification according to skin color and living conditions, an ethnic identity as such did not exist. By the early twentieth century, with the consolidation of rural black communities and slavery in the distant past, new forms of identity arose. This happened especially in remote areas, closely connected to geographical areas near the rivers due to the distribution of black communities along their shores. It was in those places where there was a favorable setting for the conservation, adaptation, and transmission of ancestral knowledge; some coming from Africa, and emerging as an adaptation to the physical and social conditions in the Americas.

Despite this, in places where black populations were living close to mestizos and the white society, particularly in urban centers; they maintained a notion of otherness. This happened because of the continuing discrimination they experienced. Indeed, as Del Valle asserts: "the definition of a system of values can be used to label a population, without accommodating changes or alternative systems, becoming the benchmark by which they determine the behavior considered as normal, and therefore, to point negatively to those who do not fit in the reference model"(Del Valle 1989: 45). In Colombia, stereotypes transmitted by the mestizo society in reference to black populations, related to a supposed predisposition to crime and laziness, about their music, 
their celebrations, and an imaginary unique sexual potency; still influences the way AfroColombians are considered as collective.

According to Gofmann, a stereotype can be used as a means to mark social differences in reference to a group of persons. When a person is identified as part of an undervalued group, he or she acquires an unwanted distinction that erases all possible positive attributes, being enrolled automatically in a standardized form of social relationship (Gofmann 1980: 57). This is particularly relevant in this discussion, because in social interaction comes to play not only what individuals say and believe about themselves and the groups to which they belong, but what other individuals or groups outside think about them. Such generalizations open the door for promoters of these communities, which undertake the protection of the values considered positive among these groups, assuming a similar generalization as a strategic reaction.

Thus, it can be said that the culture of Colombian Black Communities began to be defined based on a selection of practices that identified them as the Other; as having a cultural particularity. From there, they tried to define by their own initiative what that singular black particularity was, giving rise to a movement which facilitated this search and valuation.

However, the historical discourse produced by the elites provided the key characteristic which gave meaning to Afro-Colombian ethnic uniqueness: slavery. In effect, by emphasizing the slave past and the existence of the slave trade, the black population began to perceive that their origin and sensitivity were linked to their African past, to the point that this idea permeated their practices and beliefs. This process of recognition of otherness led, naturally, to the invention of tradition, in the effort of the 
black groups to register, objectify, select and represent the Afro-Colombian substance, so that the actual heterogeneity was disregarded to allow the definition of a single Black Culture.

Of course, in practice, this has meant making "an emphasis on ancestral, communal and sometimes remote elements; in the traditional construction of household practices, in the expression of successful adaptations to different ecosystems; in the extensive family trees or branches that define not only access to resources, but that also constitute a network through which goods and people move; in their own rationality that opposes the West; on the existence of forms of government based on elder deference; and a system of specific representations that are clearly expressed in funeral or healing practices, as well as a rich oral tradition" (Pardo 2001: 64). This type of strategy contested the discourse of the white nation, built from the elites and state institutions, in which the existence of indigenous and black ethnicities contrasted with the not ethnic mestizo majority.

Because this process was led by intellectuals, politicians, and religious leaders, that did not represent the totality of the black population, the limitations for understanding the particularities of certain groups was clear, in some cases too obvious. That situation preceded the recognition that the construction of an Afro-Colombian ethnicity cannot be considered a process completed.

That was the reason why, from the beginning, some rural populations resented the described process and were apprehensive of its purposes. In fact, in recent years, the terms "Afro-Colombian," "Afro-Descendant", and "Resurgent" have generated intense disputes when used to refer to black communities. However, all these terms are used 
interchangeably by the state and institutions. In recent years, the term "Black Community" has gained strength since its supporters see in it the affirmation of a counter-hegemonic discourse, focused on an ethnic identity which, while not unaware of the African legacy, emphasizes the racial and cultural specificity of black people. These ideas fit within the concept of "negritud", based on the definition of Marvin Lewis. According to this author, blackness as a concept would emphasize the existence of a context of high physical and cultural miscegenation. In this sense, the idea of "black community" refers to a hybrid ethnicity: "Blackness has the impact to revitalize interest, and placing a positive emphasis on the African cultural heritage in societies that have usually denied such values" (Lawo-Sukam 2011: 41).

It can be said that the discussion about the terminology given to account for the Colombian black population speaks of the need of this population to re-appropriate the colonial narrative that still negatively affects the identity of the group. However, disagreements are also due to the recognition of diversity within the Afro-Colombian communities, which makes its reduction to some basic common cultural elements difficult. This is not to assert that there are no shared factors (such factors are, in fact, used for ethnic mobilization), but it is clear that a risk of generalization exists.

\section{Constitutive elements of the Afro-Colombian identity}

According to Luis Castillo, the four basic elements on which Afro-Colombian ethnicity is instituted are:

1. A myth of origin: Africa.

2. A special relationship with nature and a deep identification with the territory, in this case, the Colombian Pacific coast. 
3. A shared history marked by three events: African past, slavery and the struggle for freedom.

4. A common culture in music, some religious practices and beliefs, and a distinctive approach to death.

In fact, even with the existence of regional variations, most black communities in Colombia share a set of beliefs and rituals related to the afterlife and social life. Although Catholicism has influenced their way of life and concept of the sacred, the basic cultural base is considered of African background, or at least elaborated by Afro-Colombians throughout their history. The African influence, for example, continues to inform traditional medicine practices, also in part because of the community's profound knowledge of their local environment. When Rogelio Velazquez, a Colombian anthropologist, visited coastal villages on the Pacific coast in the late fifties, he found that the black communities still used traditional medicine, based on the use of herbs and formulation of prayers. He found that the community preferred this kind of medicine, instead of scientific medicine, which they distrusted. This became evident when during his interviews with many students, they spoke of their aspirations to become healers (Velasquez 2000: 101). Similarly, Velasquez documented the strong belief in magic, which still persists in many towns in the region, while competing with other religious and medical practices.

The dominant belief in the community was that that the origin of the disease could be natural (sent by God), or due to some magic executed by an enemy. When the improvement of the patient was not achieved by house remedies, they went to a healer, who was also recognized as a sorcerer. According to Velasquez (2000: 103), many 
diagnoses were made by observing urine. According to the manifestation in the body, diseases and remedies were classified as "caliente" (hot) if they affected the upper part of the body, or "frío" (cold) if they affected the lowest part.

After determining the disease, to the person was given holy water to drink, and subsequently bathed with it. They also raised and polished images of saints known to be effective. The patient could also be cleaned with the incense of Easter bouquet, mixed with other vegetable and mineral products. After performing the entire procedure, the patient's improvement was expected. If this does not happen, the disease was not natural, but due to some magic attack related to the devil. Such attacks were the result of desire, envy or revenge, so they proceeded to identify the author of the spell, before going to the healer for treatment. The most common procedure in those cases was to pray a novena.

To affect someone magically, they used to prepare a wooden doll representing the victim; and it is later buried in a ditch in the woods. After this, a novena was performed to slowly kill the person. Common antidotes against these types of magic, especially among women who were pregnant or giving birth, were the use of images of saints, such as San Ramón Nonato or San Francisco. After praying to the image, the saint was bathed and the remaining water was given to the patient. Such practices are widespread in some villages in West Africa, among Muslims using Koranic verses that are considered of a high power. After writing the verses on paper, it is placed in water, and the resulting mixture of water and ink are given to the patient to be drunk as medicine (Levtzion and Pouwels 2000: 443).

In addition to the beliefs in traditional medicine and magic, Afro-Colombian communities are characterized by their practical beliefs associated with death. A popular 
belief is that the proximity of death can be predicted by watching particular birds. Also, it is believed that some people are able to foresee someone's death. Contrary to the big cities in Colombia, relatives along with the community do not isolate the sick, but rather join around them. The sick are offered their favorite foods and drinks, receive affection and prayers such as novenas so that they may die in peace. In some places, as in Baudo River valley and in Choco, the families prepare a special bed for the dying person with a mattress made out of cold herbs if the person suffers from fever, or of hot herbs, if he or she suffers from a cold illness. According to Arocha, these are similar to practices among the Fang of Gabon in Central Africa (Various 2008: 32).

When death happens, the announcement is made by the family to the local community. Traditionally, women help to wash and embalm the body as they sing, pray, clean and decorate the room for the vigil. Meanwhile, the men prepare the coffin and burial. The house is decorated in white, since it is considered the color of mourning, and the door is let open for visitors. The next step begins with the exposure of the corpse properly embellished to the relatives and ends when the coffin is taken to the cemetery. During the wake, a shrine is made, that becomes the center of prayers, chants, and dances. It is expected that a crucifix and a black bow or butterfly is placed on the shrine. Nearby, food is being prepared for the funeral, while the guests rest, play, make jokes, and sing specific songs made for the funeral.

According to Arocha (Various, 2008: 18), other practices include placing a glass or bowl of water underneath the coffin to keep the dead person from suffering from thirst. After the prayers, "alabaos" are sung from 8 am to 5 am, every two hours. And then they 
say goodbye to the deceased. The ninth night after the burial, the family and friends meet to strengthen their links.

The alabaos songs are usually performed by women, who are the cornerstone of the Afro Colombian liturgy. These are songs of praise and exaltation, which are performed without accompanying music during funerals, novenas, and other funerary rituals. Only when the songs are sung for celebrations in honor of patron saints then musical accompaniment is permitted. According to Arocha, there are greater alabaos to praise God, minor for the Virgin, and normal for the saints. When singers come from other regions, each one tries to amplify his or her singing for recognition, also in an effort to emphasize regional differences.

People who perform these songs are called "cantaoras" and "cantaores." When the songs are accompanied by drums, it may happen that the singer reaches a moment of emotional climax, pronouncing words in other tongues (glossolalia). In that situation some kind of revitalization of language happens: "liberalizing it from everyday purposes, and finding a new use as the emotional expression of ecstatic states" (Theissen 1987: 79). Thus, the possibility that the performers act as intermediaries before God, saints, spirits, and ancestors opens. There have been cases of possession documented by Nina Friedemann at Güelnambí River in 1969, where the attendees expressed that the saint had entered into the cantadora's head while she danced frantically as the drums played.

The "arrullos" (lullabies) are spiritual songs sung during funerals of children, or during celebrations of a saint's day. Some of these arrullos are dedicated to some of the most important saints of the Colombian Pacific, such as San Antonio, San Jose and San 
Miguel, San Martin de Porres, San Miguel, San Rafael, Santa Barbara and the Virgin, San Antonio and San Jose (Mosquera 2000: 18).

Music also plays an important role as a form of cultural resistance against the dominant power, especially through the usage of chants such as the "currulao" and the "boga." The bogas songs are poems with cadence and music, which are most commonly sang while navigating in the sea, rivers, estuaries, or during domestic and mining works. Currulao is a dance in which the marimba is the central instrument. This dance is vital for the reinforcement of social relations, entertaining the community while also allowing for the artistic protests of certain social issues.

The patron saint festivities are public and important for the entire Pacific region. They commemorate the birth and death of saints is, as well as the days of their apparitions and miracles. Musicians and dancers organize "balsadas" or river processions to the saints that navigate through neighboring towns and ports. During these celebrations, the river that runs through the region becomes like a highway filled with people in boats.

It is clear, as previously stated, that the characteristics of cultural traditions, beliefs, and practices of black communities today do not correspond to a single pattern, nor those patterns are related only to African heritage. In addition to that legacy, the discourse made to support the existence of an Afro-Colombian ethnicity recognizes that today the cultural heritage of the black communities is not due to this single source, but incorporates important indigenous and European elements. Since the arrival of Africans to the Pacific coast, they had contact with and were influenced by indigenous groups in the region. Due to the advanced knowledge that the natives had on the natural 
environment, they were soon recognized by Africans as specialists, and, therefore, some practices were adopted for their own use. An example of this is the ritual in which the "Jaibana" is invoked for healing. Jaibana is a spiritual entity of the Embera Indians, whom Afro-Descendants identified with the Devil (Velasquez 2000: 122).

It is evident that in these aforementioned practices, there are hybrid realities that are not the product of a single source, but of syncretism and negotiations. This is typical in territories that have experienced slavery, leading the slave to appropriate new symbols and imbue them with new meaning. It was in this way that the subordinate found the way to adapt the cultural systems that were imposed in their daily living, using camouflage as a technique. On the surface, slaves appeared to have accepted the laws and practices of hegemonic representation, but in reality, they aimed toward a different purpose from those followed by the dominant order (Lawo-Sukam 2011: 47). However, the discourse of difference emphasizes a set of beliefs and practices that demonstrate the uniqueness of African descent. For this reason, and according to Jaime Arocha, the use of the notion of "Africanism" is justified because it makes reference to the reinterpretation of the African memory made by the captives in America (Various 2008: 24).

\section{Socio-Political Context of Buenaventura}

The port of Buenaventura belongs to the municipality of the same name. At 6,078 square kilometers, by 2005 it had a population of 324,207 inhabitants (Suarez 2010: 12). Located between the Pacific Ocean and the "Cordillera Occidental" (Colombian Western Mountains), it borders with the municipalities of Cali and Jamundi. The town originated in the Cascajal Island, but with time Buenaventura spread to the mainland. However, because the port is located on the island, most of the economic and administrative 
activities of importance continue to take place there. High temperatures and high humidity characterize the city.

The port, controlled by the "Sociedad Portuaria Regional de Buenaventura SA", provides the main economic base of the city; since it controls $60 \%$ of the maritime traffic of Colombia and $80 \%$ of its coffee production. However, other activities are fishing, mining and agricultural production (Suarez 2010: 13).

The town was founded on July 14, 1540, by Juan de Ladrilleros, lieutenant of Pascual Andagoya, on lands inhabited by Buscajaes and Noamaes Indians. Interestingly, the adverse conditions, mainly due to climate and the hostility of the natives, made the development of the population minimal during the sixteenth and seventeenth centuries. In the eighteenth century, however, with the revitalization of mining, elites from Cali took interest in reopening the port; yet, it wasn't until the nineteenth century that the port was ready for aperture, when the route between Cali and Buenaventura was built.

Indeed, a true demographic development took place from the mid-twentieth century onward, when the country's economic growth, coupled with growing violence in rural areas, led to an increasing number of Afro-Colombians, living near rivers and mines, to move to the city in search of new opportunities.

Since independence from Spain in 1820, Colombia presented a series of conflicts that often became civil wars. The twentieth century was particularly notorious in that it was marked by three major periods of violence: the Thousand Days' War (1899-1902); the period known as "La Violencia" that extended between 1946 and 1965; and the current conflict that began in the early seventies, with complex relationships with the previous periods. 
The period of La Violencia caused the death of about 180,000 people in a country that by then had a population of thirteen million people (UNDP, 2003: 21), and while the greatest impact occurred in the Andean region, it also affected the Pacific Region. Black communities, who lived in the most isolated areas (in terms of economic relations with the state and of social investment) especially suffered the effects of bipartisan violence between the liberal and conservative political parties.

The sixties were to Buenaventura a period characterized by constant social protest. At that time, the port was the biggest in the country, but the constant improvement of its infrastructure went hand in hand with high unemployment and lack of social services, which affected the majority of the population. After several protests, in the early seventies began the process of establishing a free port that did not meet the expectations of the local people. The low transfer of resources from taxes to the municipality was one of the most frequent complaints. The free port was gradually dismantled during the eighties.

Despite its economic importance, Buenaventura is currently the poorest municipality in the Valle del Cauca. There is an unemployment rate of 29 percent (versus 14 percent of Colombia) and an underemployment rate of 35 percent. In fact, 80.6 percent of the people live in poverty and 43.5 percent in extreme poverty (of Reux 2012: 15). Also, according to data from United Nations Development Programme, the city has a deficit of around 30.000 homes, and of the existing, only 54.9 percent have service of electricity, 23.5 percent have water service, and 17.6 percent have access to garbage collection services (Núñez and Carvajal 2008: 14). 
Regarding education, according to data from 2004, basic primary coverage reached 86 percent of the school-age population, while in secondary and high school education reached 49 percent and 23 percent, respectively. A similar situation occurs in health services. Only 38 percent of the population of Buenaventura is covered by some kind of health system, which greatly affects a population that is already struggling with high levels of malnutrition and high infant mortality rates, compared with national and departmental averages (Pérez 2007: 11).

Due to its strategic position, illegal activities are commonplace in Buenaventura. These include arms trafficking and the mobilization of raw materials for drug processing and trafficking. This has led to criminal organizations to divide the city into zones of influence, and to seek alliances with illegal armed groups, contributing to the funding of violence.

The presence of leftist guerrillas, particularly the Revolutionary Armed Forces of Colombia (FARC), dates back to the eighties. This presence was located especially in the rural area, and, occasionally, settled in the town. Despite this, the armed conflict only entered fully into Buenaventura in the late nineties with the arrival of right-wing armed groups known in Colombia as "paramilitaries" or self-defense groups (Dominguez 2003: 27). Their original intention was to control the territory and expel leftist guerrillas, using direct violence against entire families and communities.

The struggle between different armed groups for the control of territory and resources has resulted in massacres in nearby towns such as Naya, Yurumangui, Zabaletas, and Bojayá, and has displaced to Buenaventura about 40,000 people in the last ten years (Ochoa 2009: 3). 


\section{ANTECEDENTS OF A MUSLIM COMMUNITY}

"We came from peasant people and we have this culture by birth: Respect for grandparents, for uncles and aunts, for older brothers, for women... So I was raised within an order, knowing what is good and what is bad. In the way I was educated, I educate my children".

(Alicia Camacho 2011)

Islamic beliefs and practices have been constantly redefined through history. In some cases, the interpretations are meant to obey purely religious reasons, but in others, the agenda is mainly influenced by political realities. This is not necessarily negative, given the fact that Islam does not establish a clear line of demarcation between religious discourses and political institutions. Sometimes even political changes, more than other dimensions, have contributed decisively to the diversification of religious experience. A clear example is the reestablishment of Sunni Islam since the eleventh century, related to the rise of the Turkish powers; or the growth of Twelver Shi'ism in Iran, linked to the emergence and fall of the Safavid and Qajar dynasties, from the sixteenth to the twentieth century.

In this vein, the socio-economic position of particular religious groups inside society and their relationship to the State decisively impact the tradition by creating religious variations with it. In other words, it is possible to affirm that in the case of Islam, rather than a unified religion in doctrine and ritual, it is a set of traditions that trace their essential beliefs and practices to a revealed book, the Qur'an, and to a set of established traditions attributed to the Prophet (Eickelman 2003: 17).

For these reasons, to describe Islam as a unique system of beliefs and ritual practices involves some form of reductionism. This framework is misleading since it involves 
favoring a particular narrative, and projecting its views on the diverse Muslim societies, past and present. Because we speak about Islam as a World Religion, there are certain assumptions regarding some abstract religious characteristics. Thus, to be clear, in this text the adjective "Islamic" is meant to refer to the narrative and religious practice in the ideal sense, and "Muslim" to refer to religious life and its institutions, as it is experienced by believers in their everyday life.

In the case of the Muslim community of Buenaventura, African Islam is not a point of reference in shaping their religious experience. This is mainly due to the lack of meaningful contact between African and Colombian Muslim communities for about two centuries. To be sure, Africa is more an idea than a tangible reality for them. In this sense, Islam in Buenaventura is defined and lived according to Shiism. However, a religious movement based in blackness was decisive for the emergence and early development of the Muslim community of Buenaventura. This appropriation of blackness was introduced by The Nation of Islam.

The Nation of Islam is a new religious movement that although can be classified as part of the Muslim World, in fact, took many of its original principles from the Baptist tradition of southern United States (Kepel 1995: 8). Founded in Detroit, Michigan, in 1930 by Wallace Fard Muhammad, the movement seeks the spiritual, mental, social and economic advancement of African Americans in the United States. Considered the Mahdi (prophesied redeemer of Islam), Fard asserted that a large number of enslaved Africans brought to the Americas were Muslims, so the true religion of the "so-called blacks" was Islam. Because of this, African Americans only recover their humanity lost by slavery when they become aware of their Islamic heritage and change their lifestyle accordingly. 
The movement expanded and became consolidated when Elijah Muhammad took the direction of the organization in 1934. The Nation of Islam has been recognized as one of the most prosperous and organized African-American organizations, although since its beginning, it exhibited a theology that could be described as controversial teaching, for instance, that black people have a racial superiority over whites. In a particular mythology, the Nation of Islam of Elijah Muhammad sustained that black people were the descendants of the Shabbaz tribe that existed millions of years ago in Mecca, in the Arabian Peninsula. However, at some point emerged a deity named Yakub, who decided to separate the black and white essences existing in the human being, so that the white would dominate over the black. After centuries of experimentation, the deity achieved its purpose, but paradoxically, the white race turned out to be inferior, so they were deported to Europe where they lived for centuries as monkeys. Eventually, they organized and established a social form based on domination, managing to submit the original black man and giving rise to slavery, by which they sought the final annihilation of blacks. In 1930, however, blacks were again found by the real God, in the person of Wallace Fard, who organized them into the Nation of Islam. The emancipation started with the call for a radical separation from society and from the culture created by the "white devil," and towards the creation of an independent black state and the final triumph of original man.

As shown by Gilles Kepel, this type of millenarianism has its roots in the fundamentalist Southern Baptist tradition of United States, seeking to reverse the reality in which blacks were subjected by the dominant white society (Kepel 1995: 23). Nevertheless, with the general improvement of the living conditions of African Americans, some of this mythology was subsequently rejected or smoothed. At present, 
the basic beliefs of the Nation of Islam include the belief in one God, Allah, in the Qur'an and in the scriptures of the prophets of God. Like most orthodox Muslims, the movement's members refrained from eating pork, drinking alcohol, and participating in gambling. In addition, the narcotics and smoking were also prohibited.

After the death of Elijah Muhammad in 1975, his son Warith Deen Muhammad inherited the leadership of the movement. Under his leadership, the Nation of Islam gradually abandoned the Black Nationalism and rerouted the movement to identify more with Sunni Islam. However, not all members agreed with the transformation, and in 1981 Louis Farrakhan took leadership of a faction that continues with the original name, retracing some of those points abandoned by Warith Deen.

Although the group's ideas emphasize the American reality, their discourse about freedom and validation of the struggle of minorities of African diaspora has drawn the attention of black populations in different countries outside of the Americas. The symbol and incarnation of those ideas was Malcolm X. A member of Nation of Islam from 1952 to 1964 , he was recognized as a charismatic leader and public figures until he let the group and adopted Sunni Islam after his pilgrimage to Mecca. Today he is considered a symbol of the struggles of black people in various parts of the world, including Buenaventura.

\section{Muslim Communities in Colombia}

The first records about Muslim presence in Colombia go back to the sixteenth century when the territory was part of the Spanish Empire. The early presence of Muslims during this period has been established through scattered data, and this presence was an isolated event without major historical repercussions (Castellanos 2010: 18). 
As in other Latin American countries, the contemporary presence of Muslims in Colombia is related to the Arab migration to the region from the late nineteenth century. However, most of those travelers were Maronite Christians and only a minority professed Islam.

These migrations took place in times of economic, political, and social crisis that affected several provinces of the Ottoman Empire during the nineteenth century, producing important displacements. The general crisis affected not only Christians of various denominations, but also Muslims and Jews (Karpat, 1985: 35). This situation of social disruption, together with the emergence of new travel possibilities due to better transportation along with the expectation of improving living conditions, generated waves of migration.

The migration of people from the Middle East to Latin America has not been consistent, but there have been times of steady influx. At the same time, in comparison to other Latin American countries, historically, Colombia has not been a country where migration is particularly favored. For this reason, although foreigners played an important role in the modernization of the country, their percentage among the local population has been minor. Fawcett and Carbo maintain that there was only one large Arab migration to Colombia, which took place between 1880 and 1930 (Fawcett and Carbo 1992: 8). From an alternative point of view, Nweihed divides the Arab migration to Venezuela, Colombia, and Ecuador into three periods. The first goes from the last two decades of the nineteenth century until the end of the First World War, the second is interwar period and, the third, extending from World War II until the end of the Lebanese Civil War (Kabchi 1997: 237). Although such periodizations are useful as they reflect changes in 
the political and territorial setting in the Middle East, they do not necessarily reflect the flow of Muslim population to Colombia. Indeed, after the birth of Israel State in 1948, a subsequent Palestinian migration took place to different parts of the world, including northern South America. In the case of Colombia, however, it was the arrival of Lebanese Muslims since the seventies that has been most salient. This population movement never really stopped, and, in fact, has become more complex in the last twenty years.

In conclusion, the contemporary presence of Muslims in Colombia requires another type of periodization that differentiates a first predominantly Arab and Christian migration period (1880-1930), in which the first communities were established. A second period (1948-1990) ranging from the creation of the State of Israel and the end of the Lebanese Civil War, in which the most predominant migrants were Sunni Muslims from Palestine and Lebanon. A third period starting in 1990, saw the Palestinian and Lebanese migration decrease, as the arrival of Muslims from other parts of the Islamic world increased. This last period is also characterized by the increase in conversions. Regarding the current number of Muslims in Colombia is not possible to provide reliable data. First, because of the lack of numerical data about the Muslim communities, and second, because Colombian government institutions, don't register information about religious affiliation.

Some estimation can be established by considering the percentage of Arab descent, although many of these were Christians or practiced the religion of their ancestors. This approach would also take into consideration the lack of knowledge about Muslims from non-Arab and converts. An estimate can be proposed by the identification of Islamic organizations, and the number of people attending the mosques, although, even 
this strategy is also problematic in that many Muslims do not have a connection to a particular Islamic organization, and many more do not attend mosques regularly. Even with these drawbacks, Castellanos estimates the number of Muslims in Colombia close to 15,000 (Castellanos 2010: 23).

In Colombia, Islam has been an urban phenomenon. At present, almost all the main cities in this country have one or more Muslim organizations, some founded in the seventies, but most of them established in the last twenty years. Maicao, Buenaventura, and Barranquilla, due to their condition of being ports and border towns, attracted the first wave of Muslim migration. However, by the early twentieth century, they reached Bogota, the capital of the country, from where they subsequently moved to other cities and towns (Castellanos 2010: 25). In general, Muslim migrants have made their niche in trading, and have had a tendency to locate both their homes and their businesses in the center of the city. Initially, the life of these immigrants was somewhat difficult since they arrived without knowledge of the local language and customs. However, due to necessity, they adapted fast and invested in trade and, when possible, encouraged their family or acquaintances to move to Colombia to work in what became a family business.

Nevertheless, due to the small number of Muslims (no more than 200 individuals in the first half of the twentieth century), and the lack of religious materials, Islamic practice in Colombia gradually weakened to almost nothing. On the other hand, because of the rural origin of the immigrants and their illiteracy, the knowledge of Islamic doctrine was for the most part elementary. For this same reason, and in order to avoid problems with the Christian majority, in this period there was not a willingness to share the Islamic creed. 
It was only until the fifties that the Arabs in Bogota began to regain interest in their original traditions, thanks to the resurgence of Muslim Migration in the country. Indeed, this new population had a better understanding of religious precepts and consciousness of their identity as Muslims, in part as a result of their experience throughout the sociopolitical changes that took place in the Middle East during the Twentieth Century. Following the civil war in Lebanon (1975 - 1990), as well as the gradual improvement of Colombian international relations, the Egyptian, Syrian, Palestinian, and Lebanese populations increased in number, and could maintain contact with their places of origin.

Simultaneously, the Islamic world experienced a revival of Islam as the source of identity and moral values, given the failure of many regimes based on nationalist paternalism, which did not fulfill the expectations of their populations. This phenomenon was reinforced by the victory of the Islamic Revolution of Iran and the Soviet invasion of Afghanistan, both of which occurred in 1979. The Islamic revival also came to Bogotá, stimulating the birth of the first organized Muslim community. The original intention was simply to give Muslims a place where they could pray and perform other rituals and teach the Islamic doctrine to members of their families. In 1979 they funded the "Asociación Benéfica Islámica" (Islamic Benevolent Association) of Bogota. By this time, the number of Muslims of local origin was virtually nonexistent. In the 1990s significant changes began for the Muslim community in Bogotá, at the same time that Muslims from other parts of the world began to settle in the city. At this point, the number of Colombian converts increased significantly, significantly reviving the growth of the community and with it, the emergence of diverse Islamic tendencies. 
One of the most remarkable changes for the Muslim community in Bogota was the appearance of Shi'a Islam, which was nonexistent in the country until the eighties. By the nineties, the Shiite presence increased, initially with the arrival of some Iranian and Lebanese people, as well as growing Shiite Islamic propaganda and publications, sponsored by Iranian organizations. During this period, Colombia established new diplomatic relations with Muslim countries, which facilitated the opportunity to contact and even study in qur'anic schools or Islamic universities, introducing currents as Salafism and Sufism.

Important Muslim organizations were established in the seventies in Maicao and Buenaventura, and in the last twenty years, in Medellin, Cali, Santa Marta, Pasto, Cartagena, Barranquilla, Bucaramanga and San Andres.

\section{History of Buenaventura Muslim Community}

For purposes of temporal analysis, the history of the Muslim community of Buenaventura is presented here in a periodization divided into four phases. This division is based on four dominant interpretations of Islamic doctrines adopted by the majority of the group during a period of time. These changes were not only due to religious motivations but to changes in the social milieu and the need for taking advantage of given opportunities.

The first phase, which runs from 1960 to 1980, covers the origins of the community and its consolidation under the influence of the American religious movement "Nation of Islam." At this time, there were more individual affiliations, making it necessary to speak of a group rather than an actual community. More than Muslim families, it was 
individuals united around a common cause. It was in this period that we see the creation of a legally constituted organization, and the struggle to establish the first Islamic institutions in the city. The axis of influence was the United States, more than any Islamic country, and was the moment when the ethnic nature of the community group was more pronounced.

The second stage runs from 1981 to 1991 and is defined by the beginning of a crisis within the group, which was made up of individuals and some Muslim families. The crisis was caused, in part, by external difficulties related to the loss of doctrinal reference. Local problems also began to arise due to changes within the Afro-Colombian population, and lastly, internal tensions which triggered by the debate about universal Islamic values and local interpretations of what it meant to be a Muslim. One of the main points of discussion, was the necessity to become more aware of the daily needs of women, men and children of the Community, and not to be consumed by the political and social fights. A progressive detachment from political ideas from the Nation of Islam took place at this time, beginning a period of contact and experimentation with other Islamic trends, particularly with Sunni Islam.

The third phase is from 1991 to 2002 and is characterized by the adoption of Shiite Islam and the proximity to Iran, more specifically to the religious institutions located in Qom. During this period, it is possible to observe a numerical and institutional weakening of the community, caused not only by the change of the religious affiliation, but by the absence of several of the most skilled leaders. To be sure, some salient members migrated to other countries to deepen their knowledge of Islam; others left the community because they considered that the ethnic claims were no longer the focus of the group, at a time 
when new opportunities emerged in Colombia for Afro-Descendant and Black organizations.

The fourth stage that goes from 2002 to the present is characterized by the appearance of a well-defined institutional framework, established by community leaders after their return to Buenaventura. This stage is marked by a growing masculinization of the community leadership in public spaces and the expansion of the group to the city of Cali.

\section{First stage: Origins (1960-1982)}

As discussed above, the first decades of the twentieth century were characterized by an increasing migration from rural population to the main urban centers. In the case of Buenaventura, the attraction was the seaport and the requirement of labor force, which was supplied by nearby towns. The newcomers had no awareness of labor rights or any form of work organization. As the city gained growing national status by the mid-sixties, the conditions became more complex for Afro-Colombians, who soon realized that there was a hegemonic discourse that not integrates them as an important part of society. On the contrary, they were portrayed as an inferior population.

At the same time, a growing number of Colombians began to gain access to the education system (although in unequal conditions), exposing the population to ideas of social movements. Thus, while there was an awareness of the value of traditional culture and social organization, for many, it was evident that it was necessary to seek a new framework that allowed them to understand their current situation, and to organize toward the demand for labor rights. Thanks to this growing social awareness, new 
organizations, religious-based and secular, began to appear simultaneously supporting the mobilization and recognition of minority rights. As we saw in the first chapter, these groups laid the foundation for an Afro-Colombian movement, initiating the discussion about the conditions and the real role that the black populations play in the Colombian socio-political reality.

One important outcome resulting from this change of horizon was the revisiting of the past of Afro-Descendants in Colombia, which was almost complete inexistent in Colombian historiography (Wabgou 2012: 23). For Afro-Colombians it was clear that the dominant discourse should be rejected, so they sought new standards that enabled them to redefine their ethnic particularities. Like other communities in the Americas, the return to Africa became almost an obligatory reference in recovering an important link that was lost and ignored during the centuries of enslavement and Christian indoctrination.

The United States was another vital reference point, due to the intensity of struggles that African Americans were facing in their own context. Thus, the ideas of Marcus Garvey, Malcolm X, Martin Luther King, among others, were known and discussed by young workers in Buenaventura during the 1960s. In general, the Muslim community of Buenaventura traces the entrance of Islam to the port to the arrival of a particular worker in trade boat. His name was Esteban Mustafa Melendez, and he visited Buenaventura in various occasions beginning in early 1960. This version is confirmed by some of the older members of the community, such as Alicia Camacho and Saturio Rivas.

There is not much information about Stephen Mustafa Melendez's life. He was a U.S. citizen born in Belize and worked on the ships Bursh Trader and Santa Mariana, which belonged to a company called Company Lykes Lines from New Orleans. The 
company, which apparently belonged to priests, was bought by Aristotle Onassis in 1980. Soon after Esteban Melendez pensioned, ending his relationship with the members of the port community.

During the trips that he made to Buenaventura, in route from New Orleans to Chile, Esteban Melendez took advantage of his stay in the city to talk to port workers about the Nation of Islam movement. These visits usually took place four times a year and lasted two to four days, depending on whether the ship was heading from the north to the south or south-north bound. The methodology he used was the model promoted by the movement in the United States, in which he questioned the Afrodescendants about their true origin, their real tradition, their true values and their place in society. This strategy sought to bring the black person to an awareness of the narrative and methods created by the local white elite to facilitate and maintain their domination over black people. After posing the problem, listeners were eager for an alternative discourse that explained the true nature of African descendants and their rightful place in the world.

"I started a search, and began to find my African roots: why were Africans enslaved, how was the life of the slave, or how were our women, and so on. And that's when I started to get angry, and then, I started going to the Nation of Islam" (Rivas 2011).

This work began sporadically by Melendez in 1962, and by 1965 he had brought together a group of about 25 Afro-Colombian individuals who considered themselves members of the Nation of Islam. All lived and met in La Pila, and later in La Playita neighborhoods located in the island of Cascajal, Buenaventura. Back then, as it had been for a long time, their homes were built on wooden stilts. Due to these conditions, they did 
not have a proper place, and thus, organized their meetings inside big houses of some members. Some of the original adherents were Jose Rosas Costello, first leader during Melendez absence and currently living in Panama; Manuel Gamboa, known as "Caspinche"; Solomon Bente, now living in the United States; and Saturio Rivas, now living in Cali. The group was originally composed solely of men, but a couple of years later it began to welcome women, among them, were Alicia Camacho Garcés and Mariela Rivas. In a short period of time, the group had dozens of members and hundreds of supporters. By that time, the group was mainly integrated by young people, aged between 18 and 30 years, who originally sympathized with leftist ideas and, at least some of them, were part of the Communist Party.

"Then I talked with them, because they (the Muslim group) always liked to talk much ... they began to show me books and talk about black Muslims in the United States. Then I began to realize that Islam was my original religion. Then I started to turn away from leftist groups, because I got to thinking: "They also discriminate against us, I have nothing to do here... then I'll search my origin" (Camacho 2011). Apparently, because the Nation of Islam was a U.S. movement, some people showed reluctance to be part of it, as it was considered a new form of U.S. penetration in Colombian society. Other opinions were in the direction of considering that the very idea of God was an imposition and they saw it oppressive. In this case, they followed the atheist precept supported by leftist groups. Overtime, however, the skepticism and suspicions were set aside, buttressing the group's growth and organization around the 
teachings of Melendez, who accompanied the community for nearly two decades, until 1980, when he returned to give his last farewell and announce his retirement.

The religious discourse that followed this phase, was based on the ideas set out by Elijah Muhammad and Malcolm X. According to these voices, Blacks had to find their own identity far from the Christian tradition, reaching all the way to Africa, the cradle of the original man and of the original religion for Black people: Islam. As Gilles Kepel affirms, adopting an Islamic identity speaks directly of the need to demonstrate an otherness in relation to the system of dominant values that excluded them (Keppel 1994: 28).

In Buenaventura, during this period, the religious emphasis was on the Islamic ideas and values that could serve the community in terms of organization and mobilization, and not so much on the inherent spiritual worth. For this reason, the Muslim movement easily established relations with other movements working for the vindication of the black population in Colombia. This dynamism also led to the formalization of the group, and to the founding of the Islamic Association of Colombia in 1974, the first Muslim organization to obtain legal recognition in Colombia. This allowed the group to continue to grow and, indeed, soon after the first Muslim families began to appear. Although having an established leader was considered important, decisions were made in groups, according to consultation among members. In this way, the community managed to avoid tensions and facilitated the consolidation of a collective voice. This was no meek feat, considering the few Islamic referents available.

For many years the group lacked a solid religious base, and, indeed, is not possible to know the grade of knowledge of Meléndez about Islam in general, or more 
particularly, about the beliefs and practices of the Nation of Islam. In fact, his very occupation, which allowed him to keep in touch with the new converts in Buenaventura, possibly was an obstacle for his deepening of religious knowledge. Also, we should keep in mind that Melendez visits were spaced and short. For these reasons, we could safely state that, at least for this period, the Muslim identity of the community was more an aspiration than a reality.

Because the local Muslims did not have an Islamic point of reference to which they could compare their community to, and due to the lack of Muslim immigrants in the port, we could perhaps think of the emergence of this Muslim community mainly as the result of improvisation and adaptation. In other words, this young Muslim community managed to shape their idea of Islam from very limited resources. To begin, information about Islam during the sixties and seventies was scarce. Second, the material that was available came from the Nation of Islam, an organization that offered a limited portrait of the religion, presenting a mixture of various teachings rather than providing the views from traditional Islamic schools. Lastly, the ability to acquire or have access to the Qur'an directly, or any classical Islamic sources for that matter, was simply non-existent during the early years of the community. For these reasons, at this time, membership was essentially inspired by the need to create an alternative identity that legitimated social and political actions, rather than by the conviction and acceptance of Islam as a system of religious beliefs and practices.

Due to the political and social focus of the group, meetings were essentially established to debate civic problems that affected the local population, such as violence and exploitation to which they were object, and to plan collective action in order to 
achieve recognition of their rights. Interestingly, dietary restrictions, such as no consumption of pork or alcohol, despite being known, were not seen as particularly important for those who became Muslims in this period. This is quite telling, since the Nation of American Islam has a strong emphasis on nutrition, banning those foods that kept Blacks in disadvantage (Kepel 1994: 17).

According to the older members of the community, it was not until several years later, when the community finally had access to an English translation of the Qur'an that the members realized they had not been performing the Muslim prayer properly. Rituals such as the fasting or the payment of zakat were simply unknown. As it can be expected, the Islamic rituals designated for weddings, birth ceremonies, or circumcision, were not performed during those days. In fact, printed texts about Islam in Spanish were unavailable, and the few texts in English were incompressible to most of them. Amid these bleak conditions, it is not surprising that any member of the group with some skills in English, almost automatically became a leader, a position that Saturio Rivas occupied in 1969. Thus, many of the beliefs were doctrinally unfounded, and often depended on personal opinion, so it was not strange that some Muslims maintained beliefs in Jesus as Christ, the Holy Trinity, or traditional magical practices of African or indigenous origin.

\section{Second stage: Crisis and search of new models (1982-1988)}

After Esteban Melendez retired in 1979, Buenaventura Muslims lost their main source and reference about Islam. While the teachings of Melendez remained as a paradigm, the community, led by Eugenio Barcos since 1974, began to look for new Islamic contacts. The main effort initially was to contact members of the Nation of Islam, 
sending letters to various temples in the United States, which were not answered. It is important to note that, after the withdrawal of Malcolm X and Elijah Muhammad's death in 1975, the Nation of Islam lost strength in American society. Moreover, the lack of a charismatic figure, let to several tensions and the movement entered a period of crisis. When the Nation of Islam managed to recover, it was the end of the eighties, under the leadership of Louis Farrakhan in 1981. By then, the interests of the group were more restricted to the local context, which did not align with the socio-political reality and concerns of the black communities in Colombia.

At the beginning of this period, a small group of three people (Maclovio, Silvano, and Moses) traveled to the United States and managed to get some Islamic texts in English to Buenaventura. However, even with the new resources, the lack of a true religious leadership and a clear horizon caused many members to leave the group. This crisis almost meant the end of the community, which only survived thanks to the perseverance of a handful of members. Since 1982, the leadership of the community went to Juan Pablo Romero.

In the midst of this crisis, a Muslim man from Guyana arrived in Buenaventura after traveling throughout Latin America. His name was Ahmad, and very little is known about him, except that he decided to travel to the port assuming that the community was a remnant of an African Muslim community enslaved during the colonial period (Saturio Rivas 2011). After he arrived, he realized that they were a group of the Nation of Islam, and decided to convert them to Sunni Islam:

"Then he found us talking about Black Supremacy, black is beautiful, black is big, black power, all these things, and he asked a question. He 
said: Albania is a European country, all are white, but $90 \%$ of the population is Muslim. What would you do? Would you kill them?"

(Rivas 2011).

Realizing the lack of legitimate knowledge on the religion, the members of the Muslim community decided to learn about Sunni Islam with Ahmad, who stayed in Buenaventura for some months in 1979, teaching Quranic recitation and memorization. He also taught how to perform Salah according to the Sunni tradition, major rituals, and festivals. Juan Pablo Romero, adopting Sunnism, became the leader in 1982, and under his guidance, some members of the community fasted for the first time in Ramadan in 1983. One of the members shared his memory as follows:

"It was hard, very hard, and we could not do it. We entered into Islam through the Nation of Islam, and through by Sunnism or Shi'ism, so we never fasted before... He (Ahmad) taught us that fast ends at sunset, and we abstained for 15 days. After 15 days no one was fasting. And during the first three years, we could not complete fasting during Ramadan." (Rivas 2012)

After spending a couple of months in Buenaventura, Ahmad returned to Guyana and the community lost contact with him; nevertheless, before leaving, he contacted the community with the Egyptian Embassy in Bogota. As a result of this contact, Yusuf Ali, a member of the diplomatic corps in charge of the Business section, visited Buenaventura and became interested in the community. In fact, thanks to Ali they obtained books and other Islamic materials for a couple of years, until he left Colombia. 
During this time, the community began to become aware of the existence of the Sunni and Shiite traditions within Islam, and to recognize themselves as Sunnite practitioners. This momentum toward Sunni Islam was reinforced by Abdul Rahman, a member of the community that managed to contact Bilal Phillips, a Muslim promoter of Jamaican origin, who during that time was in Costa Rica. He supported them with more materials and by facilitating a scholarship in Saudi Arabia for one member of the community. The winner of the scholarship was Nielsen Gonzalez (Ali Abdur-Rahman), who for three years studied at the University of Medina, and then returned to Buenaventura to become the leader of the community. At this time, they attempted for the first time to have contact with other Muslim communities in other cities of Colombia, which interestingly, were in a similar process of consolidation. Thus, they maintained sporadic communication with Muslims from the Lebanese community of Maicao. However, when the influence of Shiism started to spread in Buenaventura, that relationship weakened and almost ended by early 1990s (Castellanos 2010: 38).

\section{Third stage: Adoption of Shi'ism (1989-2000)}

The rise of Sunni Islam failed to attract the majority of Afro-Colombian Muslims, probably because of the orthodox, or Salafi ${ }^{3}$ influence it had in Buenaventura. To be sure, the main achievement of Sunnis during those years was their proselytist message toward a more traditional Islam. Other issues that hindered the growth and stability of the movement toward Sunnism in Buenaventura was the low income and poverty in the region, and the lack of financial funding needed for the creation Muslim infrastructure

\footnotetext{
3 "Salafiyya is the name given to those who follow the ideas and practices of the righteous ancestors (alsalaf al-salih). This "salafi" approach rejects later traditions and schools of thought, calling for a return to the Qur'an and the sunna as the authentic basis for Muslim life" (Martin 2004: 608).
} 
such as the building of a prayer room. This dire situation left the community members constantly seeking support.

After the triumph of the Islamic Revolution in 1979, members of the Iranian diplomatic corps around the world took interest in raising awareness of Shiite Islam in the West, and in establishing contacts with local Muslim communities. Due to the existence of an Iranian Embassy in Bogota, over the years, Ambassador Ali Yusuf Arafat became aware of the rumor about the existence of Afrodescendant Muslims, who were believed to exist as a community since the time of the slave trade in Western Colombia. The diplomat decided to visit Buenaventura and offered scholarships in religious training to local Muslims at the newly opened Shiite madrassa in Buenos Aires, Argentina. Several members took advantage of this opportunity, including Adil Montano, and other young men who had recently converted to Sunni Islam. The education that came from this new opportunity, along with the dwindling influence of the Nation of Islam among the younger generation, led the community to a series of debates about their religious orientation, finally deciding to adopt Shi'ism in 1989.

While originally the group of Muslims consisted of individual people, over the years friends and family members also adopted Islam. Eventually, the families of these members had a mixture of both, Muslims and Christians, and some were completely Muslim. As early as the nineties, there were second-generation Muslims who were educated from childhood according to Islamic values from the Shiite tradition. By then, the bulk of the community, which was around 600 members, identified as Shiite, leaving almost no trace of earlier rhetoric and practices of the group. However, some community members never abandoned the ideals of the Nation of Islam, and adopted Shiism only 
superficially, if they did not reject it totally. Others, who had left the Nation of Islam, became Sunnis, and even though a minority, they are Sunnis still today.

\section{Fourth stage: Consolidation (2000-2012)}

In recent years Muslims have entered a new phase with a more mature community. They have already organized into permanent institutions that respond to the basic religious needs of believers. In fact, the Mosque and the Islamic Cultural Center, are both called the "City of the Prophet," and they located on Rockefeller Avenue, one of the most important roads in Buenaventura. Built in 2000 and with a capacity of 60 seats, the mosque has a prayer room, a library, a kitchen, and it hosts an online Muslim radio station. The Silvia Zaynab Institute, meanwhile, provides education from kindergarten to high school to low-income population. While the school existed since 1981, irregular payments, coupled with the gradual decrease in the number of Muslims, led to its closure in the late nineties. In 2000, the institution reopened, and saw an increase from 45 students in that year to 148 in 2008. Although the orientation of the school is religious, 40 percent of its students are not Muslims.

The visible leader during this last stage was Sheikh Munir Valencia, originally known as Carlos Valencia Potes. He adopted the Islamic name of Munir and converted to Islam at 18 in 1985. After finishing high school, he obtained a scholarship to study Islam in Argentina in 1989, when he was 22. At his return, he assumed for the first time the leadership of the community, following the departure of Sheikh Nielsen. By that time, the community was again expanding, and about 70 or 80 people assisted to the prayer room for the Salat al Yumma (Valencia 2011). The next year he was selected to study at the 
Islamic university city of Qom, in Iran, where he received several years of training in Quranic recitation and Sharia. After that, he began a university career. Munir Valencia concluded his Islamic studies in 2000 and returned to Colombia, assuming again the direction of the community, consolidating at the same time the adoption of Shiism by the community. Under the leadership of Sheikh Munir Valencia the community obtained its current institutions: the Mosque and the Silvia Zaynab School.

During this phase, due to the better opportunities for religious education, Muslims of Buenaventura became more familiar with Iranian Shiism. However, the Iranian influence has entailed a process of masculinization, in the sense that women in the earlier phases played a greater role in decision-making than they do now. This does not mean that they are absent from religious life, but male dominance in meetings and activities at the mosque contrast with the more visible role women played in the past. Simultaneously, the sheik has become the central figure for the community, a novel approach for a people that used to resolve their problems and discuss future actions by consensus since its inception in the sixties. Indeed, the Iranian Shiite religious model puts weight on the religious leader, greatly affecting the tradition consultation, although it has not disappeared.

This process of iranization of some aspects of the community has occurred in part because of frequent travels to Iran by some local Muslims, but also because of the new generation of leaders that are in training in Qom, both for the community in Buenaventura and in Cali. In addition, some community members were born in Iran or spent some of their childhood years there, reinforcing the Middle Eastern influence. However, in Buenaventura, this tendency should not be understood as a process of 
alienation of Muslims from their social context and from the reality and traditions of Afro-Colombian people. Traditional culture and ethnicity continue to play a role, as will be shown, but it is clear that members of the community do not want to lose a level of knowledge and practice of Islam that has been difficult to acquire. This has meant adjustments and negotiations in order to interpret the Iranian teachings along with the context and needs existing in Buenaventura. In fact, from the beginning, the community has been recognized as an Afro-Colombian institution. As such, other people in Buenaventura think of them, and expected them to behave according to "Black identity." For this reason, local people expected that Muslim institutions work together with other non-Muslim organizations at the local level, toward the general improvement in living standards of the black community.

This vitality is also manifested in the continuity of Islamic practice despite the migration of its members. Many Muslims have moved to Cali, sometimes with their family, or have married there. Despite this transient context, links to Buenaventura are not lost, and strong contacts are normally kept as family members spread among the two cities (Amirah 2011). The main cause of the continuous movement to Cali is that, in many ways, Buenaventura is a satellite town in relation to Santiago de Cali, the provincial capital. For this reason, it is common for people of Buenaventura to move there for university studies, to find new employment opportunities, or for business. Due to the increasing number of Muslims in Cali, in 2003 they obtained permission by Sheikh Munir to create an Islamic school and a prayer room (musala) in the city, which was named Al Kawthar. At present, there are about 100 Muslims that are still considered part of the same community. Although they maintain some relations with the Sunni 
community of the Al Noor mosque of Cali, a distinction is still recognized among them, not only because of their religious perspective, but also because of ethnic identity.

Currently, the Islamic Center of Cali has begun to gain some prestige and independence from the Buenaventura headquarters. This change is a reflection of the improved opportunities for education, economic prosperity, and social integration for Muslims in Cali, compared to those living in Buenaventura. For this reason, although Buenaventura Muslims are known for their emphasis on the need to educate the individual, these possibilities are greater in Cali, whose community has a larger and more diverse number of professionals. Also, although conversions continue in Buenaventura, the community has more dynamism in Cali.

Naturally, the problems and challenges faced by Muslims in Cali are different from those facing Buenaventura. Their history as a religious group working for the vindication of Afro-Colombian minorities is often unknown in the capital, where the predominant view of Islam is more related to the image presented by mainstream media. To be sure, in Cali the common opinion about Muslims is that they are an intolerant and violent religion from the Middle East. Thus, the use of the veil, the performance of prayers in the workplace, abstaining from alcohol and pork have generated more misunderstandings in Cali than in Buenaventura. Moreover, faced with the growing individualism of the culture in Cali, Afro-Colombian Muslims maintain the idea of Buenaventura as the original place where the real community and family life takes place. 


\section{AFRO-COLOMBIAN ISLAMIC IDENTITY}

Islam has the solution to all problems. If a problem has no solution; it is because I have no knowledge, or something is missing in me, or something is not clear for me yet, or I misunderstood something, or because something I have not learned, or because I did not want to accept something important, because I could not think well.

(Rivas 2011)

\section{Identity and Religión}

Identity is a contemporary problem, since although identities have not existed in all human societies throughout history, only in modern times has identity become a problem of study for Social Sciences. This statement is particularly true in the case of religious identities, whose evolution has been analyzed even more recently (Ammerman 2003: 3). Indeed, because people in the modern world have tended to lose the communitarian and physical relations that traditionally linked them to a specific religion, in many countries individuals can freely choose the manner and time in which they are religious, and even their belonging to a particular religion. This creates a problem with respect to a particular religious identity, because although identities are generally thought to be built, contextualized and partial, religious identity is thought to be completely real. This can lead to conflict, as the religious identity does not merely exist in an ideal plane, but is lived through social interactions that take place within religious narratives.

In this sense, personal stories are affected by actors, ideas, institutions, and experiences, socially considered religious (Ammerman 2003: 4), and thus contribute to defining identity. This religious narrative is defined less by transcendent experiences or 
in reference to the sacred; but more frequently, religious experiences are mediated by rituals, prescriptions and institutionalized discourses that are considered religious by those who practice them, or by the society of which they are part. That is why it is possible to form religious identities without direct experience of the sacred, or sometimes even without the belief in the tenets established by some tradition.

For this reason the basis of religious identity is arguably more related to the adoption of institutionalized religious narratives, than with some transcendent experience of the sacred. Of course, this is not to deny the validity of religious experiences, or to say that they can only take place within the space of institutionalized religions, but it is clear that in the context of the Muslim community analyzed in this work, the legitimacy of spiritual searches and their exploitation as agents for social action, are supported in the membership of an institutional religion.

Such membership, or the strength of the religious narrative, does not necessarily imply immobility or inflexibility. On the contrary, as observed in the studied community, Muslims appeal to other traditions and discourses, both Islamic and non-Islamic, and even non-religious, to construct their identities, despite their varying degree of understanding of the Shiite religious tenets. However, in that exercise, they contribute in a sometimes unconscious way of continuously redefining the religious narrative of the community. As Calhoun says, "tradition becomes more of a verb than a noun" (Ammerman 2003: 219), and despite the emergence and consolidation of an initial Muslim identity and original vindications around the values of "negritude" and "Africanism", Buenaventura believers have been open to experimentation and adoption of 
new elements, enriching their religious narrative while redefining their Islamic identity in the process.

This section presents and analyzes the characteristics of the Muslim community of Buenaventura as a religious group. To do this, some relevant aspects of Islamic belief and practice as they are understood by community members, are presented.

\section{Religious Beliefs}

The basic criterion for the identification of the Muslim community is adherence to the Islamic religion. In this sense, there is a whole set of principles of faith that is shared and have been assimilated over the years, to the point that today they can be recognized as a Twelver Shiite group. However, this has been a long process, and many principles of faith were known only years after the emergence of the group, and it is still possible to find former members of the community who do not know some aspects of the officially shared doctrine. This is due to the many stages of development of the community, which has passed through the Nation of Islam, Sunnism, and Shiism, leading its members to assimilate doctrinal changes in different ways. Additionally, the cultural heritage of African descendants, which combines different elements of African tradition with a Christian framework, is a common heritage that operates surreptitiously for some members of the group. This phenomenon is understandable since the community was formed from the guidance of leaders and information from the outside, and not from direct contact with a traditional Muslim community.

Religious inculcation of children occurs mainly in households, but since the community does not want, nor (due to its small size) has the ability to, isolate itself from 
its social environment, there is a relatively good understanding of Christian Catholicism, both of doctrine and practices. This is reinforced during the school years, since most community members studied in non-Muslim schools.

Finally, one aspect to consider is that most of the members speak about religious matters in everyday language. The Spanish language comes from a long Christian tradition, which sometimes makes it difficult for the researcher to try to determine if there are in fact overlaps between the Islamic and Christian beliefs in question, or if apparent similarities are due to the linguistic constraints imposed by the majority culture, and reflect the difference between what Muslims want to say and how they are obliged to say it.

After the above preamble, a basic set of beliefs exists that is shared among the community members, making it possible to define them as a Muslim group. Those beliefs include the belief in one God (Allah), in the Prophets and in the final judgment. To this, they add the belief in the Quran as the last message transmitted by Muhammad, the last messenger of God. Community members also believe in angels and jinn, as well as in pre-destination. As a Shiite community, they also place great importance on Ali ibn abu Talib, the Prophet's son in law, and on the imams. These concrete aspects are especially visible inside the formal Muslim community, especially in the mosque. The reason for this, according to the community leaders, is an interest in maintaining good relations with the rest of the Muslim communities of Colombia that are mainly Sunni. However, there is general confidence in their Shiite identity: "One reason why I say that this community will not change to be Shiite, Imamite, and Muslim is because Ahlul Bait clarified all the problems that arose in Muslims after the prophet's death, and until today." (Rivas 2011) 


\section{Religious Practices}

In Islam, as in other religious systems, beliefs are fundamental in defining membership to a religious group. However, ritual life is the visible aspect of the belief, and the ulama have historically placed great emphasis in it. For this reason, some experts have stated that Islam is a more an orthodoxy than an orthopraxis (Eickelman 2003: 14). Indeed, as Malinowski stated, religion is above all "a mode of action as well as a belief system," and that action is primarily a social action. As Clifford Geertz said, "there is not a religion of one person, just as there is not a language of one person". Although individual experiences should not be discounted, we are primarily talking about socially shared actions and beliefs.

Therefore, when referring to religious behavior, we often speak of rituals. These are actions with strong symbolism, reflecting religious beliefs, since they are directed to supernatural beings or forces. In this text, the definition of Stanley Tambiah is adopted. According to him, a ritual is "a culturally constructed system of symbolic communication. It is constituted of patterned and ordered sequences of words and acts, often expressed in multiple media, whose content and arrangement are characterized in varying degree by formality (conventionality), stereotypy (rigidity), condensation (fusion), and redundancy (repetition).” (Tambiah 1981, 119)

As will be seen, the community of Buenaventura has adopted a series of rituals that allow them to identify as Muslims. Since these rituals serve as codes of social action, their importance stems from the fact that while they resemble the rituals performed by other Shiite communities, these religious actions serve a purpose specific to the collective 
life in the local Colombian Pacific community. So, following a traditional Islamic pattern, there are some actions with special importance, as they constitute the basis of Islam as a daily social reality. These are the so-called five pillars, which refer to specific beliefs and emphasize the action that reflects communion with the basic principles of faith. These are the profession of faith, prayer, fasting, paying taxes and the Islamic pilgrimage.

For communities of converts, which constitutes most of the Muslim community of Buenaventura, the shahada has an additional significance because it has come to be seen as a rite of passage comparable to Catholic baptism, with which Afro-Colombians are more familiar. In fact, there is a tendency among many members to not consider their sons and daughters as real Muslims until they have performed the shahada in a conscious and free manner. That usually takes place during puberty or as young adult: "she [her daughter] will do the testimony of faith as she wants, right now I do not know. When I was young, I did when I was seventeen.” (Montaño 2011)

In Shi'ism, unlike Sunnism, Salat doesn't necessarily separate each prayer time, and in Buenaventura, it is a common practice to combine the prayers of Zuhr with Asr, and Maghrib with Isha, so the five prayers are performed three times a day. This has sometimes been misinterpreted by Colombian Sunnis, especially in cities like Cali and Bogota, as they consider that Muslims of Buenaventura pray only three times a day, falling into the fault of Bida (innovation).

Friday prayers (Salat al Yumma) have a special character. For the occasion, men and women gather at the mosque in Buenaventura or Cali. Initially, the Sheikh makes an 
introductory presentation in Arabic, which includes some prayers and thoughts, and then talks, in Spanish, about general issues affecting the local community or some of its members. He can also present an issue related to Islamic beliefs or practices with local applications. Thereafter, Muslims are placed in rows facing the city of Mecca and follow the movements of the Imam, located in front of the whole group. In earlier stages of the community's establishment, men and women prayed together, and Muslim women did not wear the veil. However, in recent years it has become common to divide the two groups, men on the left and women on the right, in keeping with the guidance of the Iranian ayatollahs. A special feature that distinguishes the Muslims of Buenaventura as Shiites is the practice of placing a stone in the place that will support their forehead during prostration.

However, the practice of prayer was procedural, and in early times it was not considered an important precept. As states an old member of the community:

"And all (the information) came in English; it did not come in Spanish at all. Then we prayed in English, like the Nation of Islam. We did not do the Salat we do now ... (some years later) we started to learn and to recite the Quran. We learned al-Fatiha, and we were able to do Salat" (Rivas 2011).

Still, only the most committed members, who are usually adults, try to fully comply with the schedule of the five prayers. Among the younger members, there is the idea that prayer can be a spontaneous and free act, which seeks divine support: "I pray when my mother is sick, when my mom feels bad, or when I'm sad: I ask God to help me. 
When am I not doing well at school, when my mom reprimands at me, I tell God that I will not return to do that. I ask him to put me on good paths" (Layla 2011).

Fasting is currently one of the more important rituals for the Muslim community of Buenaventura, but its implementation was gradual. In fact, the first time members fasted was in 1983, when the community already had existed for about twenty years. Other practices of the Islamic calendar were accepted more readily, including the feast of Eid al-Fitr, along with other specifically Shiite rituals, such as the feast of Ashura, in which the assassination of Imam Ali ibn Hussain is remembered and commemorated.

In the 1990s, fasting became an institutionalized practice which the Muslim community of Buenaventura remains committed to; the same commitment was not witnessed with tax payment for the poor (Zakat). Commitment to this provision has been difficult in the community due to the harsh living conditions of many of its members. Only the growing education level and relative success among some members of the community, especially in Cali, have allowed for some form of aid distribution and support for the work of Da'wa (spreading Islam). Also, in the last ten years, members have raised funds for the Feast of Sacrifice (Eid al-Adha), not only from Iranian organizations, but also from Arab communities in northern Colombia, and more recently from the Hizmet Movement of Turkey.

Due to the low levels of income among members of the community, performing the pilgrimage to Saudi Arabia (or hajj) has been largely impossible. . Therefore, during the early stages of community history, Mecca was an ideal place that nobody thought possible to travel. However, in the last ten years several Muslims could carry out the 
pilgrimage with the support of Iranian Islamic organizations that paid for flights, as well as providing funds for visiting important Shiite shrines.

The consumption of halal food is another element of Islamic practice that has not been fully practiced by Muslims in Buenaventura, where ritually slaughtered animals, according to the precepts of Islamic law, are unavailable, and consumption of pork and alcohol is common among Christian people: “I was starving there because I don't like pork, and a friend told me: there is nothing else to eat.” (L. Montaño 2011). However, better living conditions and an increase of trade at the port, have more recently allowed for the procurement of halal food.

Both the persistence of local cultural elements and the celebration of traditional Colombian festivities are observed with the conscious intention by members of the community to avoid isolation from their broader social environment. Thus, the Buenaventura Muslims festival calendar includes celebrating birthdays, Mother's Day, the end of the year, the festivities of the Virgin Mary, and Christmas. To these are added festivities and Islamic practices which also form an important part of family life and relationships between parents and children. It is at home, rather than at the mosque, where children learn to pray, where they listen for the first time about the Prophet's life, and become at least acquainted with the Qur'an.

\section{Funerary rituals}

One of the current objectives of the community is the establishment of its own cemetery, for which they have sought support from Muslims abroad. This place is 
considered necessary because about twenty Muslims have died since the birth of the community, and the current funerary custom practiced in Colombia clearly goes against several Islamic precepts, including the common practice of conducting autopsies, which violate the principle of care and respect for the dead body.

According to Islam, once a person is deceased, whatever the cause of death, he or she has the right to four ritual acts that are the responsibility of the community. The body must be washed, it must be covered, prayers must be performed for the soul of the dead person, and finally, the body must be buried. However, because autopsies are a common practice in Colombia in order to establish the causes of death, Muslims can only perform posthumous rituals after the completion of the legal proceedings. This goes against the Islamic principle that the burial should be done as quickly as possible after death. Another contravened Islamic principle is the prohibition of the transfer of the dead body from one place to another. The usual practice, because of the autopsy requirement, involves moving the body from the family home or the hospital to the laboratory, and then finally to the mosque, enabling the physical damage of the cadaver. However, the most important principle contravened in normal custom is the violation of the sanctity of the body. Therefore, the handling of a corpse is generally considered a desecration of a person.

This is not to assert that Islam necessarily goes against conducting post-mortem examinations, as scholars of the Shia and Sunni traditions have justified its implementation in specific cases, related to the good of the community and scientific 
development. However, Islam is against the routinization of autopsies, since there is no specific benefit derived from it (Jomeini, 1991: 244).

Currently, two of the most recognized Maryad al-taqlid, the ayatollahs to Sistani and al-Khu'i, agree that performing autopsies is a desecration of the human body which must be avoided by the deceased's family. Despite this, in places like Colombia where the law requires an autopsy's implementation in order to determine the causes of death, so as to rule out criminal activity, Sistani recommends the families follow the laws of the country in which they live and allow autopsies to take place. In those cases, Muslims are not held responsible for the desecration.

For this reason, although autopsies are a problem that worries the community, the greatest concern about the rituals for the deceased is the treatment given to the person after the funeral. In Colombia there are two types of burial: vault and underground, and Muslims prefer the latter mode because it conforms to Islamic law. In the case of Buenaventura, most of the burial process is carried out by funeral companies that follow a procedure determined by rules set by the state. These companies provide services to the families of the dead person, including selling coffins, transfer and arrangement of deceased, vigil, funeral, and burial or cremation. This model is inspired by the practice done in the United States, presenting a model of standardization that is against many Muslim and Afro-Colombian traditions.

Overall, one of the reasons why Muslims opt for this type of service is due to practical concerns. Not only are funeral companies responsible for the entire process, but also for conducting the respective legal procedures (Bedoya 2006: 24). These companies 
also offer a reduction in funeral costs, while satisfying public health standards established by the Colombian government. In addition, although the current procedure involves some non-Islamic aspects during the preparation of the corpse and burial vaults, the growing religious diversity of the country has meant that these companies are willing to accept changes to the protocol, according to the beliefs of the family. Nevertheless, sometimes even Muslims are buried in vaults and not underground since the costs of a burial ground is higher.

When death occurs, the religious leader, or another member of the Muslim community delegated by the Sheikh, is called to lead the ritual acts taking place. If the body is at home and the death certificate already exists, the Sheikh frequently takes charge of washing and shrouding the body. If the deceased is a woman, the Sheikh instructs a woman family member of the deceased to perform the ritual. Meanwhile, the family communicates the death to their extended family and friends, so the body stays in the house for a time. This practice corresponds with the traditional Catholic funeral; however, traditional Afro-Colombian funeral songs such as alabaos are not permitted since Sheikh Munir Valencia is against them.

When the preparation of the body is carried out by a funeral company, the Sheikh is more limited in his capacity to act, and only performs the prayers when it is in the mosque and the tomb. In cases of underground burial, when the family owns the land in the cemetery, the grave is permanent. However, this is not a usual situation in Buenaventura, due to the low income of most families. For this reason, the disposal of corpses in temporary vaults is more common. There, the corpse remains for four years, 
after which the body is removed and, if the family of the deceased makes a payment, the skeletal remains are placed in a smaller vault. If the family does not have the resources, or they do not want to pay for the service, or are unable to be contacted, the remains are discarded or buried in a communal grave.

For Muslims, the corpse must be buried in soil, and any other form of funeral is prohibited. If there is no opportunity to place the body in an underground grave, the family can choose, temporarily, an alternative burial - for example, in a niche or crypt but in so far as possible, a final move to a tomb of land will be the obligation of the believers involved. After death, family members, or the Sheikh, visit the cemetery with some regularity in order to clean the tomb of the deceased. According to those interviewed, this brings special benefits for the dead and for the believer.

Muslim graves are distinctive among the cemeteries of Buenaventura, since they are oriented in the opposite direction to most. This is because of the Islamic provision that the body position should be with the head in the direction of the qibla. For these reasons, the purchase and legalization of land in order to establish a cemetery as Muslim has been one of the projects the community has invested significant energy.

\section{Social Aspects}

Islam, as stated above, is not an invariable system of beliefs and acts, but it takes place in specific societies and cultures. Therefore, although the religious jurisprudence refers to issues of social and family order in the private and public sphere in part the success of Islam as a world religion is its adaptability to different cultures over time. In 
that sense, the mere description of Islamic society as it appears in literature is not enough for the comprehension of the social reality of the community in Buenaventura.

The starting point should be the consideration of Muslims as a community of African descent. And accordingly, to analyze the group from its local context, that is, the condition of marginalization and poverty under which have historically affected the Black communities in Colombia.

\section{The Muslim Family}

The family is the smallest social unit that allows a group of Muslims to pass from being simply a group of believers to being a real community. In that sense, a differentiating element among Afro-Descendants groups, contrary to traditional Islamic social organization, is the important role played by women, not only in the economic maintenance of the family but in its public representation and in decision making. Whether in rural areas or more recently in the city, in formal or informal work activities, the importance of black women is a phenomenon as present today in Colombia as it was in the past.

Several researchers have drawn attention to the fact that family leadership among black populations is more feminine than masculine (Parra 2011: 24). That happens because of the stability of the feminine presence within the family unit, since usually it is women who assume the task of raising children and allow the existence of the family itself in the long term, even in the absence of men. Furthermore, the strongest relationships in traditional black communities given by kinship and community can be considered a network of domestic units of this type, in which the role of women is more 
fundamental than that of men. Around that matrifocal nucleus arise various unions of affection, rather than ordinary marriages, which temporarily reinforce the core. In families where husbands have left the family, male authority is exercised by others, such as stepparents or siblings of the mother, sometimes temporarily (Gutiérrez 1968: 167).

Because this pattern is repeated from generation to generation, grandmothers tend to be at the center of extended families. This weight of female leadership makes men, once they have reached adulthood, return frequently to their mothers' house. Temporarily, they can also contribute to the mother family or look for some support. In this organizational model, the vital activities revolve around the female figure, so in addition to being a mother and housewife, she responds in large part to the economic and social needs of the family. This does not mean that the male role is absent, since, in fact the family ideal remains the nuclear family in which a man is the head, but this only occurs in a limited number of cases (Gutiérrez 1968: 173).

Only in the last two decades, due to the implementation of Colombian laws on the duties of parents, it is possible for women to require fathers to contribute to the maintenance of their children. And even today, because of the high level of displacement due to violence, it is common for women to take full financial responsibility for the family. It is also common that children remain with their grandmother in rural areas, while the mother moves to the cities for work. There, in the cities, Afro-Colombian women often serve as maids, as cooks or in informal sales, often lacking social security benefits.

It is worth clarifying that the male tendency of increased mobility has a higher incidence in rural areas, while in cities such as Buenaventura, wage labor (either as 
workers in the port or in other services) provides the stability that facilitates the establishment of more permanent marital relations. However, due to the permanence of cultural values and patterns, often the man leaves his previous family to start a new one. In that sense, Islam has introduced among Afro-Descendants the idea of a more stable family unit consisting of a husband, a wife, and their offspring.

In the case of Muslims, families tend to be more stable once formed, but the biggest problem is the challenge for members of the Islamic community to build themselves a family to begin with. This is because the number of young men and women is limited and those within this small group, despite being coreligionist, are not necessarily compatible. As a result, many Muslims establish romantic relationships outside the community, which is not necessarily considered negative by community members. One reason may be the hope that the partner eventually will adopt Islam.

Only a few Muslim families follow the ideal pattern of a family under the direction of a man, with his wife and children. Families formed by female relatives living together are more common, forming a nucleus in which there is some flexibility. Its members may come and go, with the women supporting each other in parenting, while men are involved only sporadically. These low-income families support each other based on an established distribution of tasks to each member of the household.

However, since in Colombia there is a noticeable difference in income between men and women, Muslim households with one or more male adults usually have more opportunities for economic stability than those comprised of only women and children. The low income of some Muslim families is an obstacle for participation in community activities, especially those whose household head is the mother. The possible 
collaboration between Muslim families is constrained by the limited resources of many of them, and by the fact that Muslims do not usually pay the Islamic tax (zakat), or offer donations to the mosque.

Thus, calls for participation to the mosque for Friday prayers, for reciting $d u^{\prime} a$ Khumail, or for classes of Arabic or Islamic topics, sometimes fails to attract or involve all Muslims. One way to address this gap has been to record the sermons, which are then uploaded to a website, or by the transmission of Islamic lectures over the radio.

Before leaving the parental home, some Muslims can have socialization problems, for the reason that Islamization of the family involved in some cases a relative isolation of women: "My youth was not more interesting because I always remained at home. The only way I had something special to do was when I went to Chocó, that's when I began to live a little more socially." (L. Montaño 2011) Although this situation is not widespread, it can happen as a sort of defense mechanism in a violent setting, or in nuclear families when the father has an almost unquestioned authority, limiting the possibility of women to make decisions.

\section{Status of Women}

In its early times, women who became Muslim entered the community freely, and as a way of asserting a search for identity. From the eighties, women tended to convert to Islam for marital reasons. As a result, during this period several women said they perceived a hostile environment in which Muslim women were viewed as potential romantic partners and not as companions in the faith: "Men went to the mosque to look for women ... and then leave. They just looked for women who were attractive and had 
nice bodies.” (A. Montaño 2011) Despite having become Muslims, a strong machismo among men persisted, and they used the faith to establish temporary relationships, and children were left in the care of the woman's family, "We were Muslims, but we did not really know. We did not practice a more accurate Islam. If we knew more of Islam, then we would not have had children out of wedlock. The lack of knowledge led me to lose my way. Oh, Allah! Forgive me all my sins.” (Rivas 2011)

In the following years, the stabilization of the community led to the appearance of two different kinds of Muslim families, one with a strong male authority, and others in which the role of man and woman can be considered more as collaborative. However, this can be due to generational change, since the latter type is more common in marriages of more highly educated people under forty.

In the present day, some Muslim women tend to relate almost exclusively with other women before marriage, or with male relatives, avoiding leaving home alone, such that most of their relationships outside of their family exist in the educational space, either at school or college. A student in university asserts: "My habit is to be more with women than with men, but it is not because I am shy, but because of my religion." (Fatima 2011)

However, in the context of the Colombian Pacific region, the complete isolation of women is not possible as in the local culture there are hardly any spaces that are exclusively male or female. Because of this, courtesies that are viewed with suspicion in other Muslim communities, such as the use of the kiss in the cheek as a common greeting among men and women, are tolerated in Buenaventura as a way to not cause tensions. 
The practice of Islam and Muslim identity affect the behavior of Afro-Colombians who are part of the community, but not to the point of turning them into an isolated group with respect to the rest of the population.

Alongside these pragmatic perspectives on women coexists the archetypal vision of women playing an important but secondary role in the history of revelation. That perspective is communicated in the context of religious education at school, and in the mosque during sermons. Such archetypal figures include the Pharaoh's wife, Maryam, the mother of prophet Isa; or Fatima, the daughter of the prophet Muhammad:

"There are great women in Islam ... the wife of Pharaoh, who saves Moses. Despite being in an atheist milieu, she was one of the first people who believed in the prophecy of Moses. Naturally, Pharaoh did not tolerate that and tried by all possible means to compel her to renounce her faith ...

There were three women who were in charge of education and spiritual development of Moses: His mother, his sister and the wife of Pharaoh. Three of them fought against the oppressive political situation of that time, until they were able to get the victory in Moses" (Munir 2011).

Apart from the religious interpretation, Muslim women in Buenaventura develop their daily life in a setting where Islam is a reference and a legitimizing discourse, but not the sole basis of construction of social life. Within the scope of the Muslim community, issues such as working life, marriage, kinship, educational opportunities and overall social relations are framed within a patriarchal interpretation of Islam, where the role that wives, daughters or mothers play is valued, but considered secondary to the 
roles played by the man. This does not necessarily mean that women are subjugated or excluded, but it is clear that there are limitations within the community.

Despite the patriarchal discourse, the centrality of women in Muslim families is clear in daily practice. As for non-Muslims Afro-Colombian households, women are often those who structure family life and home continuity from generation to generation, and who transmit much of the ancestral knowledge.

Another form of social inequality that affects women in Buenaventura is related to the disparity in access to education. While in the past two decades access to elementary, secondary and higher education for minorities has greatly improved, parents still give more importance to the education of their sons than of their daughters. It is thought that men ensure greater possibility of compensation to the family nucleus. And although women have improved their educational level, this does not guarantee their equal access to the labor market.

Even among women, as shown by Martha Navarro (Suarez and Marin 2009: 148), when women with a similar educational background are compared in the workplace, there is clear discrimination in favor of those considered "white".

In the case of Muslims, the educative role is primarily a female task, and as a result, women are central figures in the articulation of the ethnic and religious values. Thus, while Islam comes to redefine many relationships and behaviors, AfroColombians do not consider their traditional culture as negative. On the contrary, they recognize it as a social foundation.

An element of this culture that has been preserved is the importance of the extended family, which is evident in the terminology used to refer to uncles and aunts: "I 
called them «Little Mom» or «Little Dad»." (Alicia Camacho 2011) This extension of the familial framework is based on the necessity to expand the networks of economic and social support, to cope with economic difficulties. A direct consequence of this is that Muslim families in Buenaventura tend to be relatively few but extensive. This contrasts with other Muslim communities in Colombia consisting of converts, which are shaped more by individuals and nuclear families (Castellanos 2010: 56).

Muslim women are seeking to maintain traditions that are important to them as Afro-Colombians. These include certain forms of crafts, stories of their past, and styles of singing. Such is the case of Alicia Camacho, composer and singer of traditional music of the Colombian Pacific. Alicia composes and rescues traditional Afro-Colombian music, such as "alabaos", leading her to become a locally recognized folklorist, especially for the work of her musical group "Caracoles Cantores". Although Alicia Camacho was an important figure in the establishment and development of the Muslim community, due to increasing Shiite influence and the strengthening of male authority within the organization, she has been relegated to a secondary position by younger male leaders.

With regard to the practice of covering women, there is no a well-defined standard in the community, as some women wear hijab, other chador, and some do not cover except when are in the mosque. Some people prefer to use it as a distinguishing mark with which to differentiate from the rest of the local population. In contrast, there are those who seek to merge Islamic practice with local elements, adapting traditional ornaments or garments of the Pacific Colombian region to cover their hair, often made 
by themselves. These individuals use fabrics, headscarves, shawls or other clothes to cover their heads, without revealing their Muslim identity.

Sometimes the wearing of the Islamic veil is understood as a challenge to established cultural and social patterns: "Well, right now I have been quiet, because no man will love me with this chador, or well covered, because men like to see more «exhibitionist» women" (L. Montaño 2011). It also can serve as a protective element: "I said so by the way men look. Men watch here (the body silhouette)... I mean, they uncover a woman with their eyes" (Aisha 2011). The veil is also considered to give a certain uniformity or equality among Muslim Women: "I feel good because we were all equal. There was no fatter or thinner, all were the same because we all had the same clothes" (Fatima 2011).

\section{Marriage}

As Ziba Mir Hosseini says, in Islam marriage (nikah) is a contract governed by a legal code, based on some religious precepts (Martin, 2004), and includes a wide range of social practices and rituals.

Traditionally, Islamic marriage is an exchange contract with fixed rules and specific legal constraints, based on a strong patriarchal ethos, and belongings to both ritual ('ibadah) and social (mu'amalat) acts. After acceptance, a dowry is paid and the woman passes under the control and protection of man, which can marry up to four wives simultaneously, or several temporary unions in the case of Shi'ism.

However, in Colombia, the Christian ideal of monogamy prevails, both legally and culturally. This is not to say that historically exceptions to the rule have not existed, 
but in traditional Afro-Colombian culture, from the point of view of people and of the law, it was common until recently that the children born to a married couple had socially more rights than children born out of wedlock.

This pattern has changed with the introduction of Islam, because Islamic jurisprudence does not consider the rights of children reduced by the circumstance of their birth. Another common practice among Afro-Descendants was to have many children, a trend that has been declining in recent years, due to higher educational levels and the use of contraceptives. In this respect, Muslims do not differ from the rest of the Afro-Colombian population of Buenaventura, seeing high birth rates in the sixties and seventies (around 8 children per family) and experiencing a drastic decrease in past decades (to around 3 children).

In the context of the black communities in Colombia, being single is looked upon very unfavorably for both men and women, but especially for the latter. This view is in keeping with Islamic law, which encourages young women to get married. Thus, married life remains the ideal, both in Afro-Colombian tradition and in Islam:

"The first thing I ask my daughter as a young lady, who has come of age, is to pray a lot. I ask her to pray as I did when I was thirteen. I asked God, I told God, «Give me a boyfriend that tomorrow will be my husband. I do not want a boyfriend who tomorrow will not be my boyfriend anymore». Then I recommended that she pray, because if she has a good husband everything is going to be very well. And not to stay single because it is best to have your soulmate as soon as possible” (M. Montaño 2011). 
Once married, many women tend to take a submissive attitude, or at least delegate much of the public representation of family to the husband. Even in the case of single mothers or divorced mothers, Muslim women's attitude is to assume such conduct toward a man of the family, in whom they delegate their representation in the community. This contrasts with the active role of women in the Afro-Colombian society, and still few cases exist of women with active roles within the Muslim community, and there is a more common tendency of Muslim women to accept a secondary role.

However, there are single or divorced Muslim women who proclaim their right to maintain their condition, not considering coexistence with a man necessary: "I did not marry because I had fear of marriage. Even my sister never married, she died unmarried. Because she did not want for her what happened to my mother, who died very young in an unhappy marriage" (Camacho 2011).

With regard to dowry, according to the Sheikh, the payment of dowry guarantees stability for women, and the obedience of the duties established under Islamic law regarding children. Because dowry it is not usually paid entirely at marriage, a portion remains as insurance to discourage divorce. In Islam, a man cannot divorce if he has not paid the dowry in its entirety. These amounts are not equal to those sometimes reached in traditional Muslim societies, given the low incomes of Buenaventura. Rather, a more symbolic payment is often made, or a promise to a future payment that is not necessarily met. "It can be something small, which really comes from the heart, from a deep feeling" (Baladez 2011).

Islamic polygamy is not a common practice in Buenaventura. While in the past it was a relatively common practice among Afro-Colombians for a man to have several co- 
wives simultaneously (Gutiérrez 1967: 172) this act is punishable by Colombian law. Moreover, Muslim women in Buenaventura oppose this practice more than women in other Muslim communities. However, according to Sheikh Valencia, polygamy should be practiced in the community as a means to avoid adultery: "So to Muslims that want to have another wife, I say: you can have her. If they say: No, my wife would not accept that, I say: it does not matter" (Valencia 2011).

When the sheikh was asked about why he did not have more than one wife, he expressed his fear of not being fair because of debts he had, which would make it difficult to provide for the welfare of multiple wives and children, although he said his wife would allow him to marry again. Also, according to Sheikh Valencia, polygamy could offer a solution to the problem of single mothers deserted by men which affects the community. Clearly, many opinions of the Sheikh and the Islamic board are not well received by all, let alone put into practice: "Being the leader is very difficult today for many reasons. I've always said, if not me, but Malcolm X or Esteban Mustafa Melendez arrived to Buenaventura and said: marry with him and you with her that would be accepted" (Valencia 2011).

\section{Temporary Marriage}

A phenomenon that was introduced because of the community acceptance of Shi'ism in the nineties was the institution of temporary marriage.

Temporary marriage (mut'ah) is a multifaceted Shia institution that has its roots in pre-Islamic times, and which differentiates Shia Islam from Sunnism, which prohibited temporary marriage from the seventh century. Temporary marriage is a contract between 
a man and an unmarried woman, whether virgin, divorced or widowed, which specifies both the duration of the union as the amount of money given to her. According to Shahla Haeri, the mut'ah usually has no legal registration or divorce ceremony, and can last from a few hours to ninety-nine years. In addition, while the purpose of permanent marriage is procreation, temporary marriage is for sexual pleasure (Haeri 1989: 28).

According to Sheikh Munir Valencia, the mut'ah meets the needs of Latin American society, in particular in the social context of Buenaventura, where the informality and provisional nature of many relationships place them outside the religious ambit.

"We put God as a witness, and for a few hours, for a few months, for a few weeks or for a year they get married. If they have children, it's like a complete marriage legalized with God. A dowry is paid and if a child is born it is fully recognized" (Valencia 2011).

For the prevailing Catholic tradition temporary marriage is unacceptable, and is a practice that is also disapproved among non-Shiite Muslims, since it is widely thought to be a veiled form of prostitution. The practice is not fully recognized by all members of the community, especially by women, who see in this a way of legitimizing sexual intercourse, particularly supported by men.

“There was something they called mut'ah. That mut'ah brought many, many problems, I listened about that and I did not like it. A mut'ah, which merely was a temporary marriage, but it turned a disorder between men and women that lasted only one week, one month, and then the man did not want more that (Muslim) sister, but married other" (Leyla 2011). 
Other common use of mut'ah was to legitimize existing unequal relations between men and women, since the latter agreed to such practice with the hope of establishing a permanent relation in the future: "I really thought: this is an opportunity to get married, to have a good home. He did not say anything but I fell in love, and then he abandoned me with my daughter" (Leonor 2011). However, due to economic conditions and social aspirations the Muslim ideal of establishing a stable relationship with a man survives. It is easier for the daughters of well-established Muslim households to get married, although this does not necessarily guarantee the success of the relation. De facto relationships are more common among men and women who have had a previous marriage; however, the tendency in recent years is to legitimize the de facto relationships under Islamic marriage. This may have to do with the recognition of the community that such arrangements are also recognized under Colombian law, which provides complete rights and responsibilities to such unions. In fact, sometimes Islamic marriage comes after the couple has passed through previous stages in their relationship, which include sex and cohabitation, and sometimes even offspring.

The perception of temporary marriage has changed over time. In the nineties, Mut'ah was seen by men as a way to have sex with women without larger obligation. But today it is valued more positively by men and women because it allows them to have a sexual behavior similar to the rest of the Colombian population, comparable to courtship and cohabitation.

"I started doing the mut' ah marriage everywhere, and some mothers were telling me «why you're doing this Islamic marriage, marrying my daughter?" I told them: I am very sorry to tell your daughter has been 
having sexual intercourse with that man for more than a year». So I'm

trying to regulate. God is in the midst of all this" (Valencia 2011).

But currently, temporary marriage is not necessarily a bad thing for many young women, since it has served to legitimize in Islam the practice of dating, recurrent among the Colombian non-Muslim population, in which two people are sentimentally and sexually engaged, without necessarily having the intent to get married and establish a family.

As for the regularity of temporary marriages, apparently these were performed relatively frequently since the early nineties, but its impact became greater after Munir Sheikh assumed the leadership of the community: When I arrived I was the "Sheikh mut'ah, that's the way they called me (Munir 2011).

Conversions for this reason are usually related, at least since the nineties, with the desire to make a temporary marriage, because this is only possible if both people are Muslim. This act permits the community to assume that the couple is officially dating. Its equivalency with the Colombian concept of engagement is confirmed by the fact that the mut'ah does not necessarily imply the continuation of the relationship in the long term, and does not necessarily imply sexual intercourse. A final point of similarity is that temporary marriage does not imply cohabitation, being still common in Buenaventura for boyfriends to live in separate homes. One point of difference is the dowry and the setting of a time period during which the agreement is in effect.

Sometimes temporary marriage is a test or trial period in order to decide, after completion, if a couple wants to assume more responsibility and commitment through a conventional marriage, if they want to enter a new temporary marriage, or if they want to 
end the relationship. Sheikh Munir Valencia says: Get married with calm. Since in any case it does not work, you can divorce, because in Islam there is divorce.

\section{Religious Institutions}

Religious institutions, places where society has institutionalized the relationship with the sacred, are important sites for religious experience and the construction of religious identities. At the same time, they support the formation of "public narratives": stories that express the sense of time and purposes of a particular cultural entity or institution. These institutions permit the creation of extensive social arenas in which religious action can occur, and provide structured religious narratives within which the autobiographical narrative of each member of the group can be experienced by him or herself.

The growth pattern for Muslim communities in Colombia usually begins by continued immigration of Muslim people into the country, a country in which the majority professes Christianity. This initial core attempts to continue their traditional lifestyle, while struggling to establish themselves and achieve some success in the new social context. These nuclei can also be formed by local people through a process of conversion, in which new Muslims joined in a group, trying to organize to facilitate religious practice while deepening the doctrine. In both cases, the immediate concern is to find a place in which to meet on Friday to pray together and to discuss common issues.

Whatever the case, initially the group meets in a small space in a house or rents a place. Once that religious space exists, the growth of the community often requires adjustment to accommodate other practices that are also part of Islamic life, such as 
funerals, marriages or fasting in the holy month of Ramadan. These moments also reinforce the ties of the group and lay the foundation for a true community life. For this reason, is necessary to designate who is more qualified to lead these tasks, as well as to ensure that religious practice is correct.

In a second stage, the Muslim group becomes large enough to require a fixed and exclusive place, which serves as a prayer hall, since at this stage the existence of a real mosque is not possible (or necessary). At this time the creation of an organization to ensure the patrimony and the interests of the community of believers occurs, thus establishing an association. This usually consists of male born Muslims and heads of household, but eventually the organizations can include Muslim women and new believers.

In a third stage the community has such importance that it manages to build a mosque, and a person who serves as Imam is employed, preferably full time. He is usually a religious specialist or a theologian from a Muslim country. At the same time, the community seeks to educate children and youth of the community within the traditional religious and cultural values, so they usually seek the creation of an Islamicoriented school.

When a Muslim community reaches this level of consolidation, they often become a pole of attraction or point of reference for other Muslims groups in nearby cities or minor villages. Eventually, the mosque may become a center of Islamization, carrying out Da'wah work among interested local people, as well as among academics and researchers (Deval 1992: 29). This classification provides an ideal scheme and does not imply that all communities in Latin America have followed the same process, as many 
know rapid development and subdivision, while others have not been able to develop and even have weakened over time.

In the case of the Muslim community of Buenaventura, the most ubiquitous institutions are the mosque and the Islamic school. Around these places personal and community stories have been built that give meaning to the collective religious life, and allow each personal experience to be read according to the changes in the institutions. However, as will be shown, these institutions have a particular history and functionality, sometimes contrary to the expectations of the community.

\section{Spaces for prayer}

The prayer center (masjid) is the central place of Islamic life. Therefore its foundation is one of the first efforts of any community. However, this does not mean that from the beginning in Buenaventura had a full-fledged masjid. Normally, believers differentiate between two types of mosques: The so-called "Jama Masjid', or collective mosque, which is a building of considerable size, often controlled by the state in Muslim countries and serves as a center of worship and community prayer on Friday. The second type consists of independent mosques of different dimensions, controlled by different groups within society (Safra 2006: 748). Since Colombia is not part of the Muslim world, the mosques that exist in the country belong to the second category, but each city has a mosque that is considered for most Muslims as Jama Masjid.

More traditionally, Muslims assume that mosques must have basic features that allow the normal course of their religious rites. Among these is a minaret, which in the early days of Islam used to be an elevated position, but has historically most frequently 
been a tower. From there the muezzin gives the call to prayer (adhan) five times a day. The mosque has a place that provides clean water, so that Muslims can perform the ablution, or ritual of cleaning, as a prelude to prayer. Inside the mosque is the mihrab, a semicircular niche in the wall indicating the direction to Mecca (Qibla); the minbar, which is usually a raised platform to the right of the mihrab, and is the place from which the person leading the ritual (imam) preaches a sermon, prior to prayer. The mosque is often carpeted or has a set of mats, upon which believers can perform prayer. These are aligned in rows, allowing orderly prostration, following the instructions of the imam (Safra 2006: 749).

In Latin American, the minority status of Muslim communities has meant that mosques, defined as buildings with the characteristics described above, are more an exception than a generality. Until recently, the only such mosques were the Mosque of the King Fahd Islamic Cultural Center in Buenos Aires, Argentina; the Sheikh Ibrahim bin Abdulaziz al Ibrahim Mosque in Caracas, Venezuela; and Umar ibn al-Khattab Mosque, in Maicao, Colombia (Castellanos 2010: 62). However, in recent years in the major Latin American capitals more mosques have been built, including Abou Bakr as Siddiq Mosque in the capital of Colombia, Bogota. Until recently, most Muslim communities in Colombia have had only a small place for prayer, with the necessary sanitary facilities for personal hygiene and cleansing ritual. Those spaces are often called musalla (prayer hall). Typically, such musallas are houses or apartments, fit for the basic needs of Islamic ritual.

In Buenaventura, early in the history of the community, the prayer place was located on Cascajal Island. By the end of the nineties, when Sheikh Munir Valencia 
assumed the community leadership, he succeeded in acquiring a one-story house in the main avenue of the city to establish the Mosque. They adapted the place to fulfill the Islamic requisites. The name they gave to the building, "Mosque No. 1, City of the Prophet", resembles the name of Nation of Islam mosques in the United States. The masjid is located outside the island and the Playita neighborhood, where most Muslims reside.

The mosque is a modest brick building, built at a lower level than that of the avenue, which allows the outside patio to have two low-rise walls decorated with images of Muslims praying or making supplications (dwa'); some words in Arabic, and two clasped hands, one of a mestizo person and the other of a black person, as a symbol of Muslim brotherhood. The outdoor courtyard serves multiple purposes according to the occasion: at times for parking, for the few community members who own a vehicle, as a place of recreation for children, or for social events. The facade is usually painted green, which is considered the "color of Islam." As is common in Islamic religious spaces, people must remove their shoes to enter the prayer hall.

The Mosque does not have a separate entry for women, as is common in other mosques. The prayer hall is a space approximately 7 meters wide and 15 meters deep. The floor is covered with mats of different sizes and patterns, all of Persian origin or style. The walls, painted white except the columns, which are green, are decorated with Koranic verses in Arabic calligraphy. Two of them are woven in golden thread over black cloth. The rest of the decoration, numbering more than a dozen elements, are wood crafts made by some women in the community, who learned this form of craft in Iran. On the east wall are the mihrab and minbar, both built in brick and cement, and painted green 
and white. The location of these spaces is not perfectly aligned to the direction of Mecca, but approximate, because of the location of the walls of the building. Moreover, the minbar is located at the left side of the mihrab and not at its right, as is common in other mosques. On the wall of the minbar, facing the space where believers are located, there is a painting of the mosque in Medina. Under the image reads a fragment of surah 62: "O ye who believe! When the call is proclaimed to prayer on Friday, hasten earnestly to the Remembrance of God, and leave off business: That is best for you, if ye but knew!" In the minbar rests a bookstand on which the Koran is located, and on either side of it there is a pair of wooden boxes to deposit coins in the first one and bills in the other. An Arabic inscription reads sadaqah (charity), while in Latin characters it reads: Ramadan. This is because it is at the end of the feast of Ramadan that resources are spent either in conducting community dinners, in preparation for the feast of Eid al-fitr, or in support of the neediest members of the community.

Down the hall, there is a space whose division is indicated by a tapestry attached to the walls and ceiling, which shows prayers in honor of Imam Husayn, grandson of the Prophet: "ia hussayn matluk, ia hussayn ia shahid, ia shari Allah." Behind it there is space of about 12 square meters that is the library of the mosque, containing about two thousand books. About 45\% are in Arabic, $15 \%$ in Persian, 35\% in Spanish, and 5\% in English. Most are texts of Shiite Islamic theology and Islamic law, however, it also contains some Sunni books, and texts about Social Sciences or Journalism. In a special place there are texts about Malcolm X, his autobiography, and other books about Black communities in the United States. On one side of this room there is a corridor leading to a kitchen, a bedroom, the restroom, and a staircase that ascends to a small terrace on the 
second floor. As decoration, in the corridor and the interior rooms are pictures of Ayatollah Khomeini and Ayatollah Ali Khamenei, as well as of Malcolm X.

It could be said that the religious leader and the community have two different perspectives of the mosque. From the point of view of the sheikh, the mosque is the compulsory point of reference, from which the Muslim community is built and perpetuated over time through instruction and guidance. And in that sense, the figure of the sheikh as a leader is dominant: "And their first reference and institution should be the mosque, the place of prayer, the cultural center. That place teaches the steps to walk in this world of kindness, love, difficulties, selfishness, betrayal, and danger" (Valencia 2011).

However, from the point of view of Muslims, the mosque is a symbol of the community's achievements, and in that sense, the sheikh's presence is due to the community. The mosque is a common good and must meet the requirements and aspirations of the community.

There is, especially among older members, the idea that the mosque, as an institution, should function as a center of support for the community. This is partly because the intention with which the first Muslim Board was created: they considered that a mosque should follow a political and social program alongside its religious purposes, as was proposed by the Nation of Islam. However, due to the conception of the mosque around more conventional Shi'ism, the mosque is understood now more as a center for religious teaching and practice.

Through the Sheikh administration, the community seeks support from Islamic countries for projects of social impact. The members of the community have criticized 
the sheikh since there is little evidence of effective aid from the United States, Saudi Arabia or Iran, and they talk about how other Muslim communities can manage to secure such support. In this sense, the way in which the Muslims of Buenaventura observe Muslim countries is arguably somewhat distorted, and so to speak, inherited some myths of western Orientalism.

This has changed somewhat with the new generations, due to a less local vision of Islam and in general, of reality. An important element in this change has been the existence of a more direct experience with global Islam, as some members have traveled to the Middle East.

\section{Religious leaders}

In Buenaventura, identifying and finding community leaders was a common challenge, due to the small size of the community. However, it is noteworthy that despite the lack of religious education, from the earliest times there were people committed to the continuity of the Muslim community. Specifically, continued work over time has allowed leaders to come from within the community, rather than depending on the arrival of Muslim sheikhs from abroad. These Afro-Colombian leaders live the everyday problems of local Muslims, and thus, with a better understanding, can become more engaged in their religious life as an Afro Colombian ethnic minority. Therefore, as the community has changed, the level of expertise of its religious leaders has improved. At one point, the current Sheikh, Munir Valencia Potes, was an exception in having completed his studies in Qom. But in the past ten years, other younger members have begun to boast similar accomplishments. 
A phenomenon observed during fieldwork was that most Muslims have rather basic notions of religion. This may well be due to the relative scarcity of religious literature in Spanish, to the low levels of reading competency among the low-income population in Colombia in general or a combination of both factors. For those reasons the sheikh is the key figure, playing an essential role in giving advice and recommendations. Many of the issues that concern or affect the community are addressed in sermons during Friday prayers.

There, in the space of the mosque, the problems of the community and the social environment are vented. Likewise, Sheikh Munir Valencia seeks to educate community members on Islamic doctrine and practice, being for some members, in fact, one of the few places available for Islamic learning. They discuss temporary marriage, or the approach that should be taken as a religious minority, or with respect to the Sheikh leadership. At this point, the Sheikh departs from the norm of other communities where the sermon tends to take a rather fixed structure and to rely on general topics. In Buenaventura sermons are not always heard silently, but always with special interest, and frequently topics of local concern are discussed. That is the space in which social, political, economic and, of course, religious issues are debated.

Despite this, there is a difference between the expectations of the sheikh and those of most of the community. It was noted that the community has seen its development over time as part of an overall process, based on collective participation and democratic exercise. For this reason, the person who conducts the religious affairs of the community is considered to be in such a role because the community has chosen him for this purpose, and he should not have special power or status. 
However, the sheikh believes that the community should recognize the religious authorities as the most important reference for daily life. This is a traditional opinion among Shiites, especially in Iran, but not in Buenaventura. It is significant that sheikh Munir Valencia often emphasizes that his youthful ambition was to become a priest. Such figures have a special respect in Colombian society, especially in rural areas. In contrast, the founding members of the community were usually critical of the Catholic clergy, belonging to leftist groups before becoming Muslims of the Nation of Islam.

The position of Sheikh Munir Valencia facing the community is not as a simple amplifier of the doctrines of Iranian Shiism. On the contrary, he plays a primary role in their accommodation to the context of Buenaventura, as well as in the introduction of local Afro Colombian cultural elements in Muslim daily life, under a religious interpretation. Although this process is not systematic, is perceived and valued by the community in their efforts to be Muslim without breaking with their social environment or Black identity. Interestingly, the Sheik uses biblical quotations or Christian themes, accompanying explanation on Koranic precepts, as a correct way to illustrate Islamic doctrine.

Some practices, such as popular healing or divination practices of African origin, persist despite the Sheik's efforts to end them, and family problems are discussed in private, with even Muslims sometimes considering the sheikh as an authority outside the domain of the Mosque. For that reason, Sheikh Munir Valencia believes that his influence would increase if the mosque as an institution were to obtain more financial resources. However, aid received by the sheikh from Iran, or received from members of the community or other Colombian Muslims is limited. Even zakat collection is difficult 
due to the financial situation of the majority of members. Given these kinds of economic challenges, the Mosque, as a religious institution, is limited in its ability to deliver aid to its numerous needy members.

Interestingly, those who expected more directives from the community are the more educated members. In this regard, it is clear that the perceptions of the community, with regard to how it should be now and in the future, changes as a person has more education and more knowledge of other Muslim communities. At this point, the members of the Muslim community of Buenaventura based in Cali have a stronger commitment to the maintenance of Muslim institutions, perhaps due to their higher incomes.

\section{Education centers and religious education}

In general, Afro Colombians attach great importance to education, not only for the social prestige it implies, but because it is the easiest way to affect upward social mobility. This trend is clear among Muslims, which compared to the rest of the working class in Buenaventura has moderately higher levels of education. This is because the founders of the community, as many of the converts, have been intellectually restless people, which may account for their interest in Islam: "I wanted to be a Lawyer ... I was crazy about Law. Possibly they could even have killed me (because of the Colombian Armed Conflict), because I would be a great defender of the common people" (Camacho 2011).

Because the Colombian government has increased access to primary and secondary education, one could say that, at present, almost all children of the community regularly attend school and have academic progress corresponding to their age. This 
contrasts with "La Playita", a sector inhabited by Muslims of Buenaventura where although there is a relatively good educational infrastructure, many children do not regularly attend school for economic reasons, child labor or violence.

The number of members of the community with university studies has increased significantly since the 1990s. Previously, they preferred educational careers, the biggest trend among young Muslims was to study university courses related to education. An alternative but less common option was to study religion in Iran. Subsequently, the experience of Iranian social and educational reality, and the knowledge of Farsi, enabled these Muslims to get scholarships for their children in university careers outside of religion: "I studied psychology, counseling of couples, and I was fine. Unfortunately, I brought my diploma to Colombia, and I have to do a validation that I find is more expensive than to re-study the career" (Montaño 2011).

Among the new generation of young Muslims in the past decade, the tendency has been to widen the range of professional possibilities. They prefer careers with the potential to make higher incomes, such as engineering, architecture, psychology or law. Most community members pursuing undergraduate studies conducted their studies at public universities, such as the University of the Pacific and the University of Valle.

On the other hand, religious education has been more a personal than a collective task, in the sense that everyone interested in learning more than the basics about doctrines or practices was obliged to study them by him or herself. Even in recent times, when religious leaders with more advanced religious training have taken control of the community, some older members look reluctant to study with younger people, from those 
they expect respect: "for me it is very difficult that a young man is teaching me Arabic. That's why I do not learn”. (L. Montaño 2011)

Only in recent times have they sought the implementation of structured training, thanks to the relatively large Islamic library in the mosque. While most books are in Arabic or Farsi, a section of nearly a hundred books are in Spanish. With these resources, as well as access to the Internet, short courses on principles of Shiite jurisprudence, basic Arabic, and an Introduction to the Quran have all been taught, among other topics. As a result, religious knowledge has become more homogeneous.

Within the community there are two Islamic schools: Silvia Zaynab Institute in Buenaventura, and a small primary school in Cali. In these places, they follow the educational program established by the Colombian State to primary and high school students, alongside basic Islamic religion and Afro-Colombian history and traditions. It is notable that most students attending these institutions are Afro-Descendants but they are not Muslims.

In our view, this happens not because a lack of identity and commitment to the community, but because those educational institutions are for new educational experiments still in development. So their educational quality is lower than those of some private educational institutions, and thanks to the improvement in the living conditions of Muslim families, it is clear why such family prefer that their children to study in nonIslamic schools, which have better infrastructure and quality in education.

In contrast, the two Islamic schools focus on people of low income whose studies are funded with state subsidies. As stated by one of the teachers of the Zaynab Silvia Institute: "I love to teach children ... to be a good teacher needs to be comprehensive, 
because some children come without eating breakfast. So, one has to understand that in our culture we have many difficulties" (L. Montaño 2011).

Although the majority of students are from Christian families, Catholic or neoPentecostal, Islam is taught as an element of cultural enrichment for students. This absence of explicit proselytizing is because the Colombian state guarantees religious freedom and worship ${ }^{4}$. Furthermore, the majority of students are not interested in adopting Islam, so the relationship with the Muslim community is one more of empathy: "We teach them something neutral. For example, we teach them how Muslims greet each other, the Muslim prayer, and we talk about God. But we do not want to influence them, because maybe some parents would be upset." (A. Montaño 2011)

As with other religious processes in the community, the creation of Islamic schools was characterized by a process of trial and error. The lack of any background and of pedagogical materials led to improvisation, and then mistakes were made, in a constant effort to improve.

It is worth noting that Islamic schools in Buenaventura and Cali are not madrasas. Madrasas are institutions in Islamic countries functioning as theological seminaries and schools of Islamic jurisprudence. Traditionally directed almost exclusively to men, these places also work as centers of political activism (Safra 2006: 724). In Buenaventura, the equivalent of the madrasa is the mosque, which offers religious education. To do this, a series of talks and, eventually, of specialized courses are scheduled. Most classes focus on learning basic Arabic and reading the Quran. However, other aspects such as religious

\footnotetext{
${ }^{4}$ Article 19 of Colombian Constitution, ratified by Law 33 of 1994.
} 
interpretation of the grand ayatollahs, the history of Islam and Shi'ism, the Prophet's life and traditions of the imams, are also taught in the mosque.

\section{Conversion}

Conversion to Islam can be defined as "a process of religious change that takes

place in a dynamic force field of people, events, ideologies, institutions, expectations, and orientations" (Rambo 1996: 27). As such, it is a complex phenomenon that can and must be understood from various perspectives.

In the specific case of Islam, conversion is confirmed by the public proclamation of the profession of faith (shahada): “Ashahadu an la ilaha illa'llah, wa ashadu anna Muhammadan rasulullah" (I proclaim there is no god but God and Muhammad is His prophet).

In traditional Christian contexts, the adoption of a different creed can be understood as a loss of one's own culture and even as a case of anti-patriotism because the conversion is often taken as a radical break with the past, and the immediate adoption of a new pattern of values or ways of understanding reality.

A common pattern in the way Muslims narrate their conversion experiences, is that it was not a sudden change due to some mystical experience or a moment of illumination, but often is described as a process. In the interpretations they offered regarding this process, they highlight Islam as having such a force of conviction, that there is no need for some supernatural experience to bring people to conversion.

Muslims in Buenaventura generally tend to understand conversion as a decision with antecedents and consequences. In other words, conversion doesn't only happen 
because of the attractiveness of the religion itself, other factors such as personal inquiries, interests, and needs also play a central role in the process. Of course, that decision includes many facets and phases. In fact, during the genesis of the community during the sixties and seventies, young people were attracted to the religion for political participation and social mobilization. At that time, leftist's organizations began to emerge throughout Colombia, and Buenaventura was not the exception. There was a great movement of ideas, and the youth participated in trade unions and peasant meetings, or by organizing discussion groups. Likewise, texts and speeches were being disseminated and discussed among the people. The case of Saturio Rivas, who converted to Islam in 1965, illustrates the connection between the leftist movements and the rising of the Muslim community:

"I went high school, and then I was part of the Communist Party ...

Salom Vente, a friend who had been in the Communist Youth League and then retired, had become Muslim. I had nothing to do with religion, you know, God does not exist, etc. Then he invited me to listen to his brother (in religion) Esteban. He invited me and I said: I'm going because this is a new form of American penetration, now they are going to poison us with such Islam" (Rivas 2011).

In the later stages of the community, conversion to Islam was gradually reduced to almost nothing, and even some members began to disengage. As early as the nineties, however, the stabilization of the community around traditional Islam and the final adoption of Shi'ism led to its consolidation and to the entry of new members, though in fewer numbers than in the initial stages. Interestingly, contrary to the tendency in other 
Colombian Muslim communities, in which conversion occurs more among women than men, in the case of Buenaventura, conversion for sentimental reasons is more frequent among young men.

To this day, conversion is necessary for the continuity of the Muslim community. This is because the number of men and Muslim women is relatively limited in a group of about six hundred individuals, which leads many young people to choose to date outside the community, hoping to achieve the future conversion of their partners.

"Until now Muslim men are not looking for Muslim women but looking for non-Muslims women. So why should one have the hope of marrying any of them, if they do not seek us. We have to look to other men who are not Muslims, and then we have to convert those men into Islam...” (Fatima 2011).

However, such conversions are not necessarily enduring, and many stop their membership when the relationship dissolves.

\section{Interreligious and inter-institutional relations}

Originally, the group was identified as a collective for the vindication of Black communities and worked along similar organizations. However, after the adoption of Shi'ism, the identification of the group became almost exclusively religious erasing the relations previously constructed with secular organizations.

In this regard, most of the current relationships occurs with Iranian NGOs, and even though the bridge is usually established through the Iranian Embassy in Bogota, it is 
possible that the connection expands eventually, to achieve cooperation from other organizations, as it happened with the Hizmet movement in Turkey.

However, the relations that they have with other Muslim communities in Colombia are not the best, considering that in other cities the existing denomination of Islam is mainly Sunni, and communities are formed mainly by immigrants from the Middle East or mestizo converts (Castellanos 2010: 67). In this sense, the emergence and growth of other Shiite organizations in other cities of Colombia, but especially in Bogotá, has contributed to the opening of the community as well as the predominance of Muslim identity outward from the Pacific region to the detriment of African descent black identity, which remains important for internal use by the community in Buenaventura and Cali.

On the other hand, in religious organizations outside Muslim communities, interest in the development of activities of interreligious and ecumenical dialogue by Christian organizations has been growing. The reaction of the community has been generally receptive. Similarly, the growing presence of religion, and especially Islam in the media, and in studies of global security, have led scholars and analysts of the Pacific region, especially in universities in Cali, to be interested in contacting the representatives of the Muslim community directly. They have been welcoming, in an attempt to gain visibility in a Christian majority context that has historically ignored the Pacific region and its people. 


\section{RELIGION AND ETHNICITY IN BUENAVENTURA}

Thanks Malcolm X, for letting us know you. Thanks Malcolm X, for living in our hearts. Malcolm X, you will live in this life and the Hereafter. (Sheikh Munir Valencia speech, 2010)

To understand the way in which local, national, and global realities are articulated in this case study, we must consider the existence of relations between the global and the local. This relationship has produced what has been called "hybrid" or syncretic identities, where cultural elements of different origins are combined. While the exact nature and meaning of these hybridizations are debated, as Canclini says, it seems that these kinds of hyphenated identities are a relatively permanent global social phenomenon (Canclini 1990: 24). This concept is particularly relevant in understanding the case of ethnic and religious minorities, and in analyzing the role of power relations in explaining the emergence of new identities and discourses.

As discussed in this chapter, the ethnic and religious identities of the Muslim community in Buenaventura are not only used for identification purposes, but it has also provided new ways or strategies toward mobilization. We can see this happening in two manners: on the one hand, they began the reinterpretation of traditions, myths, and symbols according to new frameworks. Furthermore, new agendas for real action were developed within the community after political or economic interests, have led them to become factors of change, impacting the environments in which they lived. Thus, considering that the processes of identity construction are dynamic, fluid, and changing according to time and space, it is difficult to think of the current Afro-Colombian 
ethnicity as the surviving identity from the days of slavery, or even more so, from the African continent. As mentioned above, it is clear that there is a political nature in any process of identity construction, and this is true both for the case of ethnicity as for religion, as presented below.

\section{Black Communities in Buenaventura}

In this study, "Black Community" as a concept follows the definition elaborated by the Colombian government, in collaboration with ethnic advocacy groups. According to Law 70 of August 20, 1993, Article 2, a black community is a "group of families of AfroColombian descent who has a distinctive culture, shares a history, and has its own traditions and customs. They usually have a special relation with land that serves as basis for identity and distinguishes them from other ethnic groups." Other definitions include the one presented in the ruling T422 of 1996, which considers that a black community can be recognized regardless of the possession of a particular territory. In that case, the ruling considers that the racial factor is just one of the elements that, together with other cultural values and social features, can be used to distinguish and identify an ethnic group (Ministerio de Educacion de Colombia 1996: 12). Thus, it is assumed that communities of African descent, in a political sense, possess collective rights as a distinct people, recognized by the Colombian Constitution. (ANAD 2009: 4)

According to Luis Carlos Castillo, Buenaventura had special conditions that made possible the early emergence of groups focused on the defense of the black population (Castillo 2011: 13). This special characteristic is related to the existence of the Port and the experiences gained from organized movements and unionized port workers. 
Interestingly, because half the population was below the poverty line, the phenomenon known as "norteñismo," which referred to illegal migration of young blacks to the United States in search of better opportunities began to gain increasing momentum. Once in the United States, many of them came into contact with members of the American black movement, making possible the introduction of their ideas to Buenaventura. Thanks to this, the ideological basis of the emerging groups of African descent in Buenaventura improved, and they adopted the idea of belonging to a global "imagined" black community, with networks on several continents. Thus, the discourses of Malcolm X, the Black Panthers, and even the music of Bob Marley, and Donna Summer, entered Buenaventura and contributed to the strengthening of the nascent ethnic identity. This globalized paradigm inspired the emergence of many groups such as "Juventud Quinientos" (Youth Five Hundred), the Rasta movement (Rastafarian), and the small Muslim core around the ideas of the Nation of Islam during the sixties and seventies.

Most people of Buenaventura are African descendants. According to UN data, the percentage of Afro-Colombians in the city is 88 percent (Roux 2010: 7). This percentage means the predominance of black cultures in the city, leading to many of the traditions of the places of origin to persist. To better understand this phenomenon, it is necessary to examine the origin and characteristics of black cultures in Buenaventura.

The Colombian Pacific region is a territory crossed by an extensive network of rivers that originate on the western slopes of the Cordillera Occidental, which flow in the Pacific Ocean. When slavery was abolished in 1851, much of the black population was distributed according to a "Reihendorf" or scattered pattern constructed around the banks of the rivers, called by Ulrich Oslender "a linear village in a row on the riverbank" 
(Brown 2001: 8). This type of discontinuous occupation allows them to use the best soil for growing bananas, corn, and rice, while also providing an abundant supply of fish and shrimp in the river. The waste disposal is facilitated by the small size of the population that throws it into the river, which also serves as roads.

The importance of the river led it to become the social space par excellence, around, or in which all kinds of social, cultural, and economic activities take place. The predominant form of housing is palafittes, i.e. wooden houses on stilts on the banks of the river as a way to adapt to tidal cycles and changes in water level. The focus on the river has played an important role in reshaping the African identity, moving away from the slave or even African experience as their common reference point, and toward a focus on membership to communities around a river. In this regard, people of each river are considered a given community (Brown 2001: 10). This arrangement has been transplanted to Buenaventura, where neighborhoods created by people of African descent have held a similar logic of community organization according to sets of stilt houses in different parts of the Cascajal Island. They not only share common origins ("we come from such river") but create new social relationships and collective support. Despite more than half a century since the rapid urbanization of Buenaventura initiated, the relationship with rural populations of rivers never ceased, and it is an important part of the way they understand the territory and social group.

Indeed, despite the high levels of literacy, orality remains a key element in many of the Afro-Colombian populations of Buenaventura, not only for the transmission of traditional knowledge, but for narratives about identity too. The story of the family struggles and displacement is transmitted in daily life, sometimes in poetic form, a type 
of composition known as "La Décima" (the tenth), which is composed by "decimeros" and transmitted by any member of the community until it becomes anonymous.

Traditional music survives in Buenaventura, despite the competition from domestic commercial music and from other countries. Some genres emerge such as folk heritage, but other forms of music and dance remain fluid, maintaining a creative dynamic between traditional composers and performers, and young people who have initiated interesting fusions and adaptations. Of particular importance is the currulao, played by ensembles composed by marimba de chonta (deep-toned xylophone of African origin), male and female cununo drums, two bass drums, male and female too, and two or three guasas (a type of rattle). Such expressions have continued to be attacked or at least neglected by the public and Catholic religious institutions in the city, even today. While a couple of decades ago there were some laws created to protect recognized Afro-Colombian cultural practices, in reality, the community lacks spaces for their expression (Suarez 2010: 63).

Many religious festivals are celebrated in the rivers, as are the festivities to the Virgin of Atocha in the town of Barbacoas, south of Buenaventura, where the statue of the Virgin is carried in "balsadas" or platforms created by putting together several boats. The statues are transported, visiting the villages on the banks of Telembí River. Each of the villages that are visited along the river is responsible for receiving the Virgin and hosting her procession, providing liquor, food, and singing performances. Relatives come from neighboring rivers and even from cities such as Pasto, Buenaventura, and Cali.

Further north of the port, in Choco, the town of Tado celebrate the feast of Our Lady of Poverty. Other festivities include "San Pacho" (Saint Francis of Assis) in Quibdo; the festivities of the Virgen de las Mercedes in Itsmina in San Juan river; Virgen 
del Rosario in Condoto; Our Lady of the Immaculate in Guapi; Santa Barbara in Timbiquí, among other religious festivals. It is worth noting that these celebrations are recognized only partially by the Catholic institution, since popular expressions are imbued with syncretic practices where alcohol and African, Spanish, and Indigenous traditional symbolism are present. Such traditions do not disappear when black populations move to Buenaventura but spread to the urban setting.

In Buenaventura, the relationship with other cultures allows a new syncretism between local traditions and the new ones entering the port, in part brought by those who travel abroad in search of new opportunities and that come back after a while. At the same time, the city came into contact with many outside social and cultural practices, influencing the collective values of the community.

Islam in Buenaventura emerged in "La Playita," where part of the neighborhood is exposed to tidal flow. The houses were built mainly of wood on stilts, which is a common architectural structure for houses on the banks of rivers, to protect the homes from the tides and soil moisture. This type of housing is also considered cheaper and fresher than brick houses (when they lack air conditioning). However, some parts, such as the bottom and the zinc roof, must be constantly repaired due to the rapid deterioration from the moist weather.

Many of these homes have access to clean water through illegal connections to a main pipe; alternatively water is purchased and transferred in buckets. These types of houses have three different spaces: a dining room in the back, where most social life takes place; rooms (sometimes only one or two but can reach up to four), which are used primarily for sleeping; and a front area where most of the everyday jobs are done. In this 
area, there is the kitchen, the bathroom, and sometimes a small patio or terrace. This is the place where religious rituals of the family take place and it is common to find a carpet with an image of Mecca, or other Islamic decoration.

\section{Religious Adaptations and Transformations}

Despite the importance of the ethnic identity, the community now mainly identifies as Shiite. Since community leaders studied in Iran, and sometimes are sponsored by Iranian religious institutions, their main trend is Khomeinist Shi'ism. Current Shi'ism has been powerfully influenced by the charismatic figure of Ayatollah Khomeini (19021989), as well as for the institutionalization of the Iranian Islamic Revolution. This legacy is seen in sermons as the one entitled " Irán un destello de luz" (Iran, a flash of light), delivered in 2009 by Sheikh Munir Valencia on the occasion of the anniversary of the Revolution:

"Ruhollah, Spirit of God, your legacy turns today 35 years of excitement and love. If is true a famous saying: "A father is not the one that engenders but the one who educates," then you will be my father for life. O Spirit of God, Imam Khomeini. And my house will always be the one in which you were born, my dear Islamic Republic of Iran" (M. Valencia 2011).

Nevertheless, contrary to what could be imagined, for the community, the difference in contexts and interests between the societies of the Middle East and Colombia are very clear. For that reason, Iranian politicized speeches have not been echoed in the community, which has a more pragmatic than an ideological vision of their 
life as Muslims. Of course, proper Shi'ites practices, such as the commemoration of the martyrdom of Imam Hussayn, are performed diligently, but the Iranian political agenda is overlooked.

For that reason, when addressing the description and analysis of the beliefs and practices upon which the religious life of Muslims in Buenaventura is constructed, it is necessary to differentiate those aspects according to the different stages that have marked the community since its inception in the mid-sixties. While from the beginning, Buenaventura Muslims have had political and social concerns, namely the struggle for equality of Afro-Colombians, religion soon became the main reason for organization, the main focus of their collective actions, and an important basis from which to define their identity. For this reason, any adaptation was considered enrichment, and the religious changes of the past are valued as acquired knowledge.

In this way, the Muslim community has a history of four generations, which has allowed them to create their own narrative about their future. Therefore, the adaptation of Muslim life to their socio-cultural reality is a process that began forty years ago, ultimately, portraying Islam as a common legacy that is in constant development.

This does not mean that all the descendants of Muslims come to embrace Islam. After receiving an Islamic training at home during their first years of life, many young people turned their eyes on the surrounding culture, predominantly Christian and secular, mainly because of their desire for social integration. Over time, many adults returned to Islamic beliefs and practices and became more committed, others came to see Islam as a part of their worldview and of their family life, and as a community legacy, but without 
considering themselves as Muslims at any time in their adult life. The following testimony is an example of this view:

"My children are not Muslims, not because they were not taught, but because they did not like it. They know how to do Salat, they know the Sunnah to do Salat, but they don't want to be Muslims" (Rivas 2011).

The Afro-Colombian religious universe still exists around the Muslim community. Traditionally, Afro-Colombian beliefs concede great importance to forces that inhabit the cosmos and exert control over it. In other words, despite the belief in a supreme being, which exists in most of the Bantu traditions in West Africa, there are other agents that are actually part of the everyday world order, and that are more active than the creative deity, which tends to be an idle deity. The way they relate to these forces include ritual magic and sorcery, practices that have been frowned upon by the Judeo-Christian and Islamic monotheistic religions. Until a few decades ago, a traditional vision with important elements of African origin was still dominant in many Colombian black communities, especially on the riverbanks in the Pacific region. However, under the structure of Catholic domination, the Supreme God was recognized as the main deity, while the religious fervor concentrated more on the traditional Catholic calendar, which went to replace, or rather, to hybridize, the traditional African deities.

While these traditions still remain important, especially in rural populations, the Christian revival in the second half of the twentieth century has led to the weakening of these practices and beliefs. Therefore, most of the members of the Muslim community deny the legitimacy of these religious traditions, without ever denying its real existence. 
However, these forces become reinterpreted as genies (jinn), acting in the world against the ways established by God.

It would be naive, however, to pretend that the traditional African worldview disappeared altogether, rather we can find expressions of it in the places where Islam is practiced and transmitted. This syncretism is evident as narrated by Malcolm, a member of the community:

"The day of my birth, my mother saw strange things in me but she never dared to tell me. During my first years of age, I had many unexplained fevers and headaches that did not heal with medicines... when I was a little older, seven or eight years, I began to see visions ... at fourteen, new forms of attack began to appear caused by "the enemy" and I had many nightmares... when I went to live in Cali the problem got worse."

It is significant that although in his narrative, Malcolm identifies the forces that attacked him as genies. He found no solution to his problem in reading the Koran or in Salat, but in the practices of traditional sorcerers of Santeria:

"I started looking for help on the side of Santeria or sorcerers, and they told me it was a witchcraft that they made to my mom and that I had absorbed. So we desperately sought help from Santeros in Cali, Buenaventura, and other places, until finally, we found one sorcerer that was efficient."

In his account of the healing ritual, a combination of elements of popular Christianity and African Santeria appear, while not Islamic concepts are mentioned: 
“...They made an exorcism in my room. They put me on my knees, my mom put her hand on my head, and then this man did a lot of prayers. Before that, I drank plenty of holy water, so my body could be purified ... also, during the prayer, he said that I could call upon someone who was dead, but that knew me. Then we invoke my dad's mom. We ask her for help, along with God and Jesus. We made some prayers and he gave me the first drink of water. It was in a bowl with sugar, which was supposed to work like a magnet, so when evil comes out it doesn't fall on someone else ... and when I threw up, I vomited a lot of things I've never seen, combined with saliva. I was surprised. Then the witch doctor took them, wrapped them in cotton and went to bury them in the cemetery. He said it was one of the strongest witchcraft that occurs in Africa, called voodoo, and that if he would not intervened on time, I would have gone mad, and after madness comes death" (Malcolm 2011).

This type of supernatural experiences is commonly narrated by other members of the community as well; Yusuf Sharif Arafa says:

"In our family, mostly by my mother side, there are a number of boys born with these virtues or special conditions. In Cajambre river was born a nephew whose eyes were like two light bulbs. When the lights were turned off, his eyes lit up like bulbs. After a while the child died. And there have been other cases" (Arafa 2011).

In Buenaventura, even if the person is Muslim, people believe that the real protection comes from tradition. For that reason, in each family there is a member that 
performs rituals and prayers of protection; this is usually a woman of old age. When she dies, young members are left unprotected. Similarly, the story of the apparitions of supernatural beings, despite being identified as genies, corresponds more to the popular Catholic tradition in Colombia. An example would be the practice of using allusive terminology to refer to the personification of evil, rather than directly calling him "the Devil." One of the popular names is "the man of the hat":

"I was praying, and the moment I was falling asleep, I felt my head heavy. And when I looked at the wall, the man with the hat was there. Then I began to ask, «If you come in the name of God, tell me what you need» and the man gave no answer. So, I said: «Tell me what you want in the name of God, if not, go away because I'm going to sleep», and I got back but I trembled with fear. When I was already calmed, I looked at the wall and he was no longer there" (Arafa 2011).

When asked for an explanation about this kind of experiences, members of the community, as expected, lack the cultural heritage of traditional Muslim societies, so often resort to popular Christian tradition to fill these gaps. It is thus noteworthy that some Muslims affected by witchcraft, do try to stay away from African traditions and limited themselves to Islamic practices in seeking a solution. They attend the mosque and even tried some form of healing with the Sheikh, but without being able to solve the problem. Surely, such healing by sorceries is rejected by the majority of Muslims, although they are tolerant to some Catholic religious practices: 
"A brother was going to leave his wife because she baptized their son. I

said, brother, if it is holy water I would also want to anoint him, because to pour water over a child is not a reason for divorce" (Valencia 2011).

\section{Muslims as a Black Community}

For the community of Buenaventura, the idea of Africa permits the reinforcing of values considered beneficial for the group. Against a mestizo and Christian social environment in which African culture is undervalued, the community members claim and idealize the richness of African culture:

... I always wondered when I see leaders of African descent, especially Afro-Colombians: do we really have an African identity? Does our race give us the courage to say that we carry Africa in our blood? ... Is it true that we comply with the customs of the best ancient tribes of Africa?" (Valencia 2011)

As stated above, Africa serves as an ideal. For that reason, there is often a request by the sheikh for community members, motivating them to behave in certain ways. Although the reference to Muslim doctrine as such is the most recurrent incentive for the community, the allusion to alleged African values is also common: "it makes us very sorry to say, African brothers, that today we are not meeting our traditions and identity" (Valencia 2011).

As a Black community, Muslims appeal to the African ideal as a way of supporting the effort for maintaining a neutral position in facing the violence and the Colombian Armed Conflict. In that sense, sermons are not simply aimed at strengthening 
attitudes or specific loyalties, but also seeking to keep Muslims away from problems in Buenaventura, to the extent possible:

"Your mother said to God you were people of good will. Why have you fallen so low? Why you forgot your lineage and identity? If you had African blood, these words would be the best reason to stop the internal war. Today, among people of African descent, the vast majority is killed, murdered, slaughtered, including ourselves" (Valencia 2011).

Another aspect that affects Afro-Colombian populations in Buenaventura is the idea of whitening. This is a process by which racist cultural background decreases traditions and physical characteristics of Afro-Colombians by preventing upward mobility, or through marriages with people of lighter skin. While these ideas are common among Afro-Colombians from different socioeconomic levels, black intellectuals and members black movements share an active opposition to such ideas. In this context, the Afro-Colombian community has developed mechanisms of resistance by buttressing the value of the African physical attributes and the cultural particularity of African descent (Wade 1993: 7).

Precisely because of their condition as a black community, the Muslims in Buenaventura still use the methods popularized by the Nation of Islam in order to capture the listener; namely, by confronting the individual with a series of questions, which include:

"What do you know about your origin, about your roots? Why are you in the Americas? Why do you have that name? Why don't they respect you? Why you do not respect yourself "(Valencia 2011). 
These questions were used in the same context by the Nation of Islam during the 1960s, and largely explain the changes that subsequently occurred and the particular link between ethnicity and religion. However, these ideas, despite its dissemination among marginalized populations, were not known by most, but by black people who had a particular interest or education. As Saturio Rivas says:

"I've always been very restless, very curious of books, and then I started to inform myself. I came to buy books and I started reading about many of the things they taught about my African roots. It explained why they were members of the Nation of Islam, and why were they talking about black supremacy... God being black and all black, and black, and black. And we talked about Malcolm X and Muhammad Ali” (Rivas 2011). In spite of the fact that the sixties and seventies were a time of mobilization and political agitation in Colombia, it is possible to perceive that even in leftist groups and organizations, the people of black skin suffered specific discrimination. Thus, they soon realized the need to create their own organizations to represent their particular interests and needs. This case is presented by Alicia Camacho, who entered into the group in 1968:

"I never accepted that blacks were savages who lived in trees... And when I heard about Africa, it was like a magnet that attracted me, and I said, «We must be something more, and behind us has to be something». Then I began to participate in communist groups, but I realized that within those groups existed discrimination too." 
Clearly, as Thomas McCloud says, conversion to Islam by African Americans is largely a response to racism (Yazbeck 1991: 177). In this vein, it is a reaction to a social situation in which they are not only in the bottom of the social scale, but they are not provided with clear mechanisms for improving their living conditions or for social integration. This situation, existing in Colombia, explains why the narrative from the Nation of Islam had such echo in the port of Buenaventura. Although five decades after their arrival, the conditions for black communities in Colombia changed, the improvement is not significant.

"Afro-Americans face a new kind of domination when they tell us that being African is disagreeable. They want to showcase your weaknesses to humiliate you, and are skilled in division and ostracism. So, I dare to say that we have failed as Afro-Descendants. If we want to be worthy of African descent, we must return to the same, to the genuine. We must recover our true African culture" (Valencia 2011).

Due to the characteristics of the process of conquest of the indigenous population by Europeans in the sixteenth century, and because of the type of caste society that emerged during the colonial period, in Colombia, the vision of Western Europe as a principle of civilization in opposition to the indigenous and African cultural heritage is still predominant. In that sense, the history of indigenous peoples and the African Diaspora is hardly mentioned, if not simply invisible. Faced with this reality, Muslims imposed a new look at Africa as the cradle of culture and world civilization. Under this view, Africa not only was the place of origin of Afro-Colombians, but of many important mythological, religious, and cultural references. 
In this view, Africa is not only the cradle of some of the prophets of the Jewish tradition but was the place of origin of the Semitic languages, like Arabic and Hebrew. Egypt is presented as an archetypal example of African arts and sciences that have influenced the emerging of other civilizations. As stated by Sheikh Munir Valencia: "Africa had in its hands, for more than two thousand years, the monotheistic prophecy. From Abraham to Prophet Moses, peace of God be upon them all". Likewise, the monarchy and the state would be African creations, from which other traditions and cultures have risen.

"I want us to reflect and let it be clear that the prophet Moses was African. Pharaoh decided to adopt Moses and tell his people that Moses was his son, and the people believed it, this shows that Moses had the same color skin that the Pharaoh, and the same ethnicity. Moses never was a Jew but an African monotheist" (Valencia 2011).

Against a reductionist view of African religion, stereotyped as primitive and superstitious, if not evil, members of the community have idealized the African religious past as purely monotheistic. This element, although it works for a Christian cultural environment, is more commonly referenced as a defense of a particular ethnic identity within the Islamic monotheism: "Before religions, such as Judaism, Catholicism, and Islam, in Africa there was a real philosophy where there was a supreme being, and where the dead were not lifeless, but they still existed." (Valencia 2011) As it is clear from the narratives of the community, the link that joins the Afro-Colombian ethnic identity with Muslim religious identity would be the presence of black Africans from the early days of Islam. The most known case is that of Bilal al Habashi (580-640 C.E.), one of the most 
trusted and loyal companions of the Prophet. Another important reference is Islam's long history in African territory. According to this interpretation, the religion par excellence of Africa is Islam, so it would be natural for people of African descent to return to this religion.

Of course, in this case "Africa" is an idea, which is useful insofar as it is not a reality. Buenaventura Muslims do not really try to know neither what the characteristics of African religions are, nor their history as it has been written by professional historians. In addition, the academic sources in Buenaventura are scarce, and most African descents do not see a particular utility in exploring these issues. What is considered useful, is the idea of Africa as a place of origin and source of discursive mechanisms to address exclusion.

Such mechanisms, on the other hand, are not completely original, but derived from great leaders of the movement for the vindication of the black population, and from the concepts of "Africania" or "African Diaspora." In this sense, Malcolm X has become the central figure recognized by all, as the embodiment of the effort for the liberation of blacks in all fields, as well as the voice that calls to the return to Africa as an ideal, and mainly the recovery of Islam as the original religion. For that reason, community members are interested in the life and thought of Malcolm X, directly reading his texts, gathering information online, or listening to those who have spent time studying his biography and speeches. He is cited repeatedly in the mosque as an authority in sermons and in community meetings, along with traditional or contemporary scholars of Islam. 
In the view of the community, Malcolm was a global leader, and his thought not only influenced the black population in the United States, but also people of African descent in Latin America:

"Malcolm told American and Latin American black organizations that their biggest mistake was that they had not been able to establish a direct line of communication of brotherhood among the independent nations of Africa and the black people of African descent" (Valencia 2011).

The figure of Malcolm X is instrumental for strengthening ethnic identity, while serving as an archetype of a defender of the rights of the oppressed that builds bridges with other groups working on improving the living conditions of black communities. There are images of Malcolm X in the mosque, in Muslim educational institutions, and even in some households. Among the activities of the community, there is the commemoration of Malcolm X birth, on May $19^{\text {th }}$, and for this particular occasion, celebrations are held at Silvia Zaynab School and the Mosque.

"Reflect and see that what we need is an example to follow besides that of the Prophet Muhammad (PBD), the Imams, and the great sages of the Eastern world. We need an example to follow that is ours. And that is Malcolm X: An African descendant" (Valencia 2011).

Children celebrate the life of Malcolm X, displaying his photographs and reading texts related to the occasion. After this, Sheikh Munir recites a speech.

"We see in Malcolm a father, a prince, a leader, a martyr. It was simply his essence: an absolute love for the black race. Malcolm made himself our advocate. Malcolm was the defender for the black, because for the 
love he had to African descendants, and they killed him" (Valencia 2011).

This line of thinking is not considered foreign, but is enriched by the appropriation of several Afro-Colombian figures that fought for the vindication of the rights of black communities. In this sense, the community considers remembering a long list of people, both of the colonial past and of the nineteenth and twentieth centuries as an indispensable act. Thus, semi-legendary characters (not because there is some doubt about their existence but because is little known about their real lives) are commonly quoted. Some of these were moors, slaves, or rebels who sought their freedom facing the Spanish colonial domination. Slave Agustina, is an example of heroism and resistance for destroying some estates in the area of Chocó because of the murder of her son. They also mention Barule, a leader from the Palenque of Tado, in Choco; Benkos Bioho, famous rebel leader, as well as Poland and Wiwa, of the Matuna Palenque, near Cartagena; and Catherine Luango, from Palenque de San Basilio. From the period of independence, it is common to mention Joseph Prudencia Padilla (1788-1828), an important admiral in the wars of independence, who was sentenced to death on charges of conspiracy.

In the contemporary period, other public figures are included, such as Amin Smith Córdoba (1948-2003), journalist and sociologist from Choco; Diego Luis Cordoba (19071994), political scientist and lawyer; the poet and pedagogue Manuel Saturio Choco Valencia (1867-1907), and Samuel Zapata Olivella, recognized physician, anthropologist and writer of Cordoba. International personalities have also joined the list in an effort to strengthen black pride and identity within the group. As an example, an earlier website of 
the mosque included a list of African and African descendant leaders, including Kofi Anan, Robert Mugabe, Kwame Nkrumah, Nelson Mandela and Desmond Tutu. Another historical link between ethnic identity and religious identity is often based on the rumor about the arrival of Muslim African slaves during the sixteenth and eighteenth centuries. Although historians in Colombia have not specifically studied the presence of Muslims during the colonial period, it is known that it is quite possible since there is data of their presence in the viceroys of Peru and New Spain, but by the nature of the slave process in the New Granada, their number should be quite low. 


\section{CONCLUSION}

The Muslim community of Buenaventura, as a collective, is a group whose basic identity is religious, but that is distinctive because of the ethnic affiliation of its members. "Afro-Colombian" is an ethnic identity produced by black communities in an effort to find integration in the Colombian national construction project. It is a category that is both limiting but also necessary. Indeed, the Afro-Colombian population has been recognized by individuals, society, and by the Colombian State. This ethnic category has also been useful for the construction of a legislative body with the ability to develop policies that can benefit this and other ethnic minorities.

As constitutive elements of the Afro-Colombian ethnic identity, we can mention the existence of Africa as myth of origin; a special relationship with nature and a deep identification with the territory, in this case the Pacific coast; a shared history marked by slavery and the black struggle for freedom; and the existence of a common culture represented in music, some religious practices and beliefs, and a particular connection with death.

As seen, in the middle of the twentieth century these black communities began in an effort to find cultural references that could help the group reshape their identity. This occurs as a response and a way to deal with the weakening of traditional ways of life and the need to give meaning to their marginal position in the predominant mestizo society. In that context, from the search emerged a special interest to learn more about the Civil Rights Movements of Black Communities in the United States, which allowed a group of individuals from the Colombian Pacific region to know and adopt the principles of the Nation of Islam. 
Over time, due to changes both in Colombian society and within the group of Muslims, in the late eighties, the community changed to a more traditional Islam, and, finally, to Shiism. The adoption of Islam did not imply, as expected, a mere replica of Iranian Shi'ism, but rather it developed a religious narrative that navigates along with local rituals and ways of social interaction. As evidenced, this narrative is not only used as a religious discourse, but generates actions and social roles. While Islamic religious doctrine conveys the idea of unity and homogeneity, in reality, the Muslim world consists of many religious experiences. On the one hand, it speaks to the particular needs of local communities, while on the other, its global status creates a powerful connection with millions of Muslims around the world.

In that sense, this thesis presented the way in which religious beliefs and practices are used by a Muslim community in order to strengthen its Afro-Colombian ethnic identity, in an urban context of social exclusion. At the same time, but in opposite direction, African ethnicity is connected to Muslim identity, since Islam "was" the original religion of black people. The study of the relation between ethnicity and religion is especially relevant in this case because both are important foundations of social life. This thesis presented the way in which they relate in the construction of identity, and, particularly, how religious concepts and behavior can be used to strengthen ethnic identity. Thus, in Buenaventura "Muslim" was initially an ethnicity, rather than a religious category.

Later, when social demands lost their centrality to the group, religion was placed as the epicenter of the discourse and group boundaries were extended to the potential consideration of other types of ethnic identity. It is important, therefore, to note that 
members of the Muslim community of Buenaventura are part of invisible minorities, both in terms of their ethnicity and in terms of their religiosity. In that sense, there is not a context of "normality" within which Muslim practices could be naturalized and people forget their uniqueness. On the contrary, the social context is a permanent reminder of their religious difference, and therefore, to remain Muslim is a task of constant reaffirmation.

At the same time, the existence of some form of Black identity does not necessarily imply that ethnicity constitutes the most important social reference or the main engine of mobilization. However, combined, Black and Muslim identities are not mere referents of identification, but gave way to mobilization strategies. This phenomenon occurs in two ways: on one side, the community started practices of reinterpretation of traditional myths and rituals according to new frames of reference; but also developed civic agendas within the group, in pursuit of common political and economic benefits, which led the members of the community to become agents of change, impacting the environments in which Muslims operate.

The history of Afro-Colombians Muslims is not just about a minority or an exotic phenomenon in a predominantly Catholic country. On the contrary, the phenomena studied here are the result of the historical process of Colombian society. For this reason, this community should be studied further as a reflection of the problems and challenges of the local population in a globalized world, and not as some kind of isolated implantation of the Middle East in a distant port of Latin America. 


\section{BIBLIOGRAPHY}

Afrocolombianos. Comunidad negra. 04 de 09 de 2009.

http://afrocolombianossantamarta.blogspot.com.co/2009/09/comunidadnegra.html (accessed: March 03, 2012).

Aisha, interview by Diego Giovanni Castellanos. (May18, 2011).

Almario García, Oscar. «De lo regional a lo local en el pacifico sur colombiano, 17801930.» Revista de Historia Regional y Local 1, no. 1 (2009): 11-18.

Arafa, Yusuf Sharif, interview by Munir Valencia. (May 18, 2011).

Asociación Nacional de Afrocolombianos Desplazados. Del dicho al hecho... hay mucho trecho. Análisis de marcos normativos y políticas públicas para población afrocolombiana en situaciones de desplazamiento forzado y/o confinamiento. Bogotá: Afrodes / Global Rights, 2010.

Ávila Arias, Serge Edwin, and Juan Carlos Toro Cárdenas. Entre lo Vernáculo y lo Contemporáneo: Reinterpretación de la Vivienda Palafítica en Buenaventura. Bogota: Universidad Nacional de Colombia, 2010.

Balta, Paul. Islam: Civilización y Sociedades. Madrid: Siglo XXI Editores, 2006.

Barth, Frederik. Ethnic Groups and Boundaries: The Social Organization of Culture Difference. London: Waveland Press, 1998.

Bedoya, David. Caracterización del Sector Funerario y la Tanatopraxia en Colombia. 2006. http://www.actiweb.es/menarguez/archivo1.pdf (accessed: April 22, 2012).

Bell, Catherine. Ritual: Perspectives and Dimensions. New York: Oxford University Press., 1997.

Berg, Herbert. Elijah Muhammad and Islam. New York: New York University Press, 2009.

Bolaf, Guido, Raffaele Bracalenti, Peter Braham, and Sandro Gidro. Dictionary of Race, Ethnicity and Culture. London: Sage Publications, 2003.

Camacho, Alicia, interview by Diego Giovanni Castellanos. (May 21, 2011).

Castellanos, Diego. El Islam en Bogotá: Presencia Inicial y Diversidad. Bogotá: Editorial Universidad del Rosario, 2010. 
Castillo, Luis. Etnicidad y Nación: El Desafío de la Diversidad en Colombia. Cali: Universidad del Valle, 2009.

Colombia, Comunidad Islamica de. Islam Colombia. s.f. http://www.islamcolombia.org/library/lideres\%20africanos\%20y\%20afro\%20des cendientes.htm (access: September 23, 2014).

Conyers, James and Andrew Smallwood. Malcolm X: A Historical Reader. North Carolina: North Carolina Academic Press, 2008.

El Corán. Madrid: Miraguano Ediciones, 2006.

Daniel, Martin Varisco. Islam Obscured: The Rhetoric of Anthropological Representation. New York: Palgrave, Macmillan, 2005.

De Roux, Gustavo. Políticas públicas para el avance de la población afrocolombiana: revisión y análisis. Panama city: Programa de las Naciones Unidas para el Desarrollo, 2010.

Dillon, Michelle. Handbook of the Sociology of Religion. Cambridge: Cambridge University Press, 2003.

Domínguez Mejía, Marta Isabel. «CLACSO.»Los procesos de resistencia al conflicto armado y al desplazamiento forzado por parte de pobladores rurales afrocolombianos en el municipio de Buenaventura. 2003. http://bibliotecavirtual.clacso.org.ar/ar/libros/bec (accessed: May 18, 2012).

Eickelman, Dale F. Antropología del mundo islámico. Barcelona: Edicions Bellaterra, 2003.

Eller, Jack. Introducing Anthropology of Religion: Culture to the Ultimate. New York: Routledge, 2007.

Ernst, Carl. Sufismo: Una Introducción esencial a la filosofía y la práctica de la Tradición mística del Islam. Barcelona: Ediciones Oniro, 1999.

Fatima, interview de Diego Giovanni Castellanos. (May 21, 2011).

García Canclini, Nestor. Culturas Hibridas: Estrategias para Entrar y Salir de la Modernidad. México: Editorial Grijalbo, 1990.

García, Husain Abd al Fatah. «Usos Funerarios Islámicos”.» Ahlul Bait. 2008. http://www.biab.org (accessed: May 17, 2012). 
Geertz, Clifford. Local Knowledge: Further Essays in Interpretative Anthropology. New York: Basic Books, 1983.

Geertz, Clifford. The Interpretation of Cultures. New York: Basic Books, 1973.

Goffman, Erving. Estigma: La identidad deteriorada. Buenos Aires: Editorial Amorrortu, 1980.

Gutiérrez de Pineda, Virginia. Familia y Cultura en Colombia . Bogotá: Ediciones Tercer Mundo / Universidad Nacional de Colombia, 1968.

Haeri, Shaila. Law of Desire: Temporary Marriage in Shi'I Iran. Syracuse: Syracuse University Press, 1989.

Instituto Colombiano de Cultura Hispánica. Geografía Humana de Colombia, Tomo VI: Los Afrocolombianos. Santafé de Bogotá: Instituto Colombiano de Cultura Hispánica, 1998.

Jomeini, Ruhollah. Las Leyes Practicas del Islam. Buenos Aires: Ediciones Mezquita At - Tauhid, 2008.

Kepel, Gilles. Al Oeste de Alá: La Penetración del Islam en Occidente. Barcelona: Editorial Paidos, 1995.

Klein, Herbert S. African Slavery in Latin America and the Caribbean. New York: Oxford University Press, 1986.

Kloppenborg, Ria and Hanegraaf, Wouter. Females Stereotypes in Religious Traditions. Leiden: E. J. Brill, 1995.

Klor de Alba, Jorge. «Postcolonialization of the (Latin) American Experience: A Reconsideration of 'Colonialism' and 'Mestizaje'.» After Colonialism: Imperial Histories and Postcolonial Displacements, de Gyan Prakash, 241-276. Princeton: Princeton University Press, 1995.

Kuper, Adam, y Jessica Kuper. The Social Science Encyclopedia. London: Routledge, 2005.

Lawler, Sthepen. Identity: Sociological Perspectives. Cambridg: Cambridge University Press, 2008.

Lawo-Sukam, Alain. «(A)cercamiento al concepto de la negritud en la literatura AfroColombiana.» Cincinnati Romance Review, no. 30 (2011): 39-52.

Layla, interview by Diego Giovanni Castellanos. (May 19, 2011). 
Levtzion, Nehemia. The History of Islam in Africa. Athens: Ohio University Press, 2000.

Lewis, James. The Oxford Handbook of New Religious Movements. Oxford: Oxford University Press, 2008.

Malcolm, interview by Diego Giovanni Castellanos. (May 27, 2011).

Marcinkowski, Christoph. Shi'ite Identities: Community and Culture in Changing Social Contexts. Zurich: LIT, 2010.

Martin, Richard. Encyclopedia of Islam and the Muslim World. New York: Macmillan, 2004.

Maya Restrepo, Luz Adriana. «África: Legados Espirituales en la Nueva Granada, Siglo XVII.»Historia Critica, no. 12 (1996): 29-42.

Mc Farlane, Anthony. Colombia Antes de la Independencia: Economía, Sociedad y Política Bajo el Dominio Borbón. Bogotá: Banco de la Republica / El Ancora Editores, 1997.

Midlo H., Gwendolyn. Slavery and African Ethnicities in the Americas: Restoring the Links. Chapell Hill: The University of North Carolina Press, 2005.

Ministerio de educacion de Colombia. «Ministerio de educacion de Colombia.» Sentencia T-422/96 Diferenciación Positiva para Comunidades Negras . 1996. http://www.mineducacion.gov.co/1621/articles-86260_Archivo_pdf1.pdf (accessed: Febrary 18, 2012).

Montaño, Amirah, interview by Diego Giovanni Castellanos. (May 19, 2011).

Montaño, Leonor, interview by Diego Giovanni Castellanos. (May 18, 2011).

Montaño, munira, interview by Diego Giovanni Castellanos. (May 24, 2011).

Mosquera Rentería, José Eulicer. El Movimiento Socio- Político Afrocolombiano: Caracterización y Fundamentos. Quibdó: Ediciones Licher, 1996.

Mosquera, Sergio. Visiones de Espiritualidad Afrocolombiana. Quibdó: Universidad Tecnológica del Chocó, 2000.

Museo Nacional de Colombia. 150 Años de la Abolición de la Esclavitud en Colombia: Desde la marginalidad a la construcción de la Nación. Bogotá: Aguilar, 2003.

-. Velorios y Santos Vivos: Comunidades Negras, Afrocolombianas, Raizales y Palenqueras. Bogotá: Museo Nacional de Colombia, 2008. 
Núñez Beltrán, Miguel Ángel. «Predicación e Historia: Los sermones como interpretación de los acontecimientos.» Criticón, no. 84-85 (2002): 84-97.

Núñez, Jairo. ¿Cómo romper las trampas de pobreza en Buenaventura? Propuestas desde las comunidades y las instituciones. Bogotá: Programa de las Naciones Unidas para el Desarrollo, 2008.

Okpewho, Isidore, Carole Boyle, and Ali Mazrui. The African Diaspora: African Origins and New World Identities. Blominghton: Indiana University press, 2001.

Pardo, Mauricio. Acción Colectiva, Estado y Etnicidad en el Pacifico Colombiano. Bogotá: Instituto Colombiano de Antropología e Historia, 2001.

Parra, Christian. Sistema de Cobertura Educacional Nómada para Zonas Ribereñas en el Pacifico Colombiano. Cali: Universidad Icesi, 2011.

Parrinder, Geoffrey. La Religión Africana Tradicional. Buenos Aires: Ediciones Lidiun, 1980.

Pérez, Gerson Javier. Historia, geografía y puerto como determinantes de la situación social de Buenaventura. Bogota: Banco de la República, 2007.

Restrepo, Eduardo and Rojas, Axel. Afrodescendientes en Colombia: Compilación Bibliográfica. Popayán: Editorial Universidad del Cauca, 2008.

Restrepo, Eduardo. Conflicto e Invisibilidad: Retos en los Estudios de la Gente Negra en Colombia. Cali: Editorial Universidad del Cauca, 2004.

Richard, Yann. El Islam Chiita. Barcelona: Edicions Bellaterra, 1996.

Rivas, Saturio, interview by Diego Giovanni Castellanos. (May 18, 2011).

Safra, Jacob. Britannica Encyclopedia of World Religions. Singapore: Encyclopaedia Britannica, 2006.

Sanneh, Lamin. La Corona y el Turbante: El Islam en las Sociedades del Africa Occidenta. Barcelona: Edicions Bellaterra, 2001.

-. «The Domestication of Islam and Christianity in African Societies: A Methodological Exploration.» Journal of Religion in Africa 11, no. 1 (1980): 1-12.

Silva, Renan. Territorios, Regiones, Sociedades. Cali: Universidad del Valle, 1994. 
Suárez Reyes, Felix. «Buenaventura: Una Ciudad puerto, Globalizante, Diversa y Multicultural.»XIV Encuentro de Latinoamericanistas Españoles - Congreso Internacional 1810-2010: 200 Años de Iberoamérica. 2010.

Tambiah, Stanley J. A Performative Approach to Ritual. London: The British Academy and Oxford University Press, 1979.

Terril, Robert. The Cambridge Companion to Malcolm X. Cambridge: Cambridge University Press, 2010.

United Nations Development Program. El Conflicto: Callejón con Salida. Bogota: UNDP, 2003.

United Nations Office for the Coordination of Humanitarian Affairs. Colombia: Emergencia, Informe de Situación. Bogota: United Nations, 2009.

Valencia Potes, Oscar. Factores que incidieron en la constitucion del Islam en Buenaventura. Cali: Universidad del pacifico, 2014.

Valencia, Munir, interview by Diego Giovanni Castellanos. (May 20, 2011).

—. Speech: ¿El Islam en África como Táctica de Salvación y Superación, 2011.

—. Speech: 15 años en el islam, 2011.

—. Speech: África, cuna de los profetas, 2011.

—. Speech: Buscando nuestras raíces ancestrales, 2011.

—. Speech: Irán un destello de luz, 2011.

—. Speech: Los profetas, 2011.

—. Speech: Malcolm X, 2011.

—. Speech: Somos Musulmanes Colombianos, 2011.

—. Speech: Una educación para la descolonización, 2011.

Varisco, Daniel (2005). Islam Obscured: The Rhetoric of Anthropological Representation. New York: Palgrave Macmillan. s.f.

Varisco, Daniel. Islam Obscured: The Rhetoric of Anthropological Representation. New York: Palgrave Macmillan, 2005. 
Velásquez, Rogerio. Fragmentos de Historia, Etnografía y Narraciones del Pacifico Colombiano. Bogotá: Instituto Colombiano de Antropología e Historia, 2000.

Wabgou, Maguemati. Movimiento Social Afrocolombiano, Negro, Raizal y Palenquero . Bogotá: Universidad Nacional de Colombia, 2012. 